\title{
Selective Laser Sintered Poly(L-Lactide)/Carbonated Hydroxyapatite Nanocomposite Scaffolds: A Bottom-up Approach
}

\author{
Wen You Zhou1, Min Wang ${ }^{2}$ and Wai Lam Cheung 2 \\ 1Discipline of Orthodontics, Faculty of Dentistry, The University of Hong Kong, \\ 34 Hospital Road, Hong Kong, \\ ${ }^{2}$ Department of Mechanical Engineering, The University of Hong Kong, \\ Pokfulam Road, Hong Kong, \\ China
}

\section{Introduction}

The main objective of this research is to study the feasibility of using the selective laser sintering (SLS) technology to fabricate 3D porous scaffolds from poly(L-lactide) (PLLA) and poly(L-lactide)/carbonated hydroxyapatite (PLLA/CHAp) nanocomposite for bone tissue engineering applications. There are great demands for tissue engineering (TE) and ideal tissue engineering scaffolds should possess physical, mechanical, chemical and biological properties to fulfill the requirements for tissue regeneration. These properties basically depend on two key factors; namely, material composition and scaffold architecture. To address the first issue, biocomposites seem to be a better choice than single matrix. In this study, a biocomposite, which consists of PLLA microspheres filled with CHAp nanoparticles, is developed. PLLA is chosen because it is an FDA-approved, biocompatible and biodegradable polymer which has been widely used in many biomedical applications. Meanwhile carbonated hydroxyapatite is a promising material for bone substitution as it is bioresorbable and also more bioactive in vivo than stoichiometric hydroxyapatite. In terms of scaffold architecture, modern rapid prototyping (RP) technologies such as stereolithography apparatus (SLA), fused deposition modeling (FDM), 3D printing and SLS offer excellent flexibility. However, materials used for SLA are typically acrylics and epoxies, which are non-biodegradable. At present, only very limited choices of materials are available for FDM because the materials have to be in the form of filament. 3D printing is also limited by the availability of suitable binders to meet the biological and strength requirements of tissue engineering scaffolds. In contrast, SLS has already been used to produce porous poly $(\varepsilon-$ caprolactone) (PCL) bone tissue engineering scaffolds based on actual model of minipig and human condyle (Partee, Hollister et al. 2006), therefore it has a great potential for tissue engineering scaffold fabrication and has been chosen for this project. However, SLS has been developed primarily for industrial applications. At present, it is not financially viable to process most biopolymers or their composites in commercial SLS machines because the amount of material required is quite substantial and the costs of biopolymers are very high. 
Furthermore, most available biopolymers are not in the appropriate powder form for the SLS process. In order to reduce powder consumption, Lee (2006) has modified a Sinterstation ${ }^{\circledR} 2000$ SLS machine to allow small quantities of biopolymer powders to be processed. In this study, three major issues were addressed. Firstly, the nanoemulsion method was applied to synthesize CHAp nanospheres $(\sim 20 \mathrm{~nm})$ as the osteoconductive filler for building the nanocomposite scaffolds (Zhou, Wang et al. 2008). Secondly, PLLA microspheres and PLLA/CHAp nanocomposite microspheres $(\sim 5-30 \mu \mathrm{m})$ were prepared by the oil-in-water and solid-in-oil-in-water emulsion solvent evaporation procedures respectively (Zhou, Wang et al. 2007). Finally, with the modified SLS platform, prototypes of bone tissue engineering scaffolds $(\sim 10 \mathrm{~mm})$ with meso-porous structure were successfully built from the PLLA microspheres and PLLA/CHAp nanocomposite microspheres (Zhou, Lee et al. 2007; Zhou, Lee et al. 2008). This study demonstrated a bottom-up nanotechnology approach in tissue engineering which assembling smaller scale simple biomaterials (nanoemulsion synthesized nanoscale particles, emulsion solvent evaporation prepared microscale nanocomposite spheres) into larger scale complex macro-scaffolds by laser technology. Fig. 1 shows the summary of relative scales of substances/scaffolds concerned within this study.

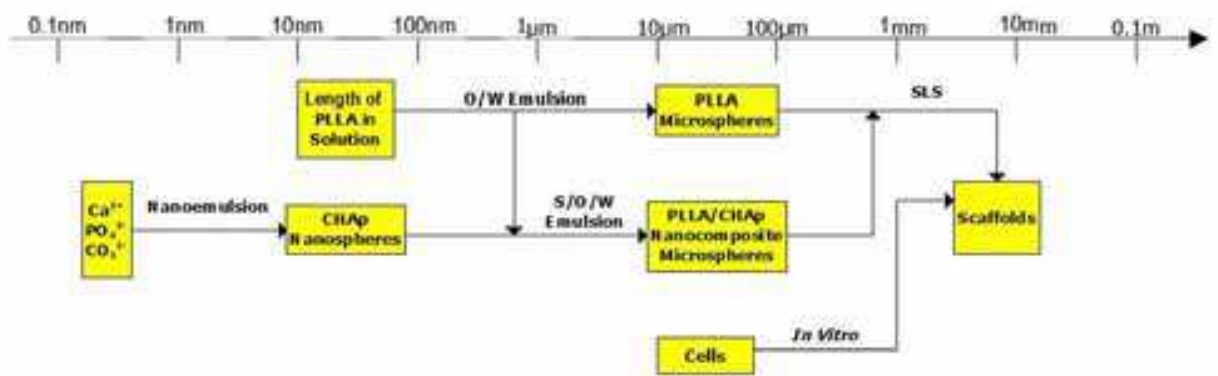

Fig. 1. Summary of relative scales of substances/scaffolds concerned with this study.

\section{Synthesis and characterization of carbonated hydroxyapatite nanospheres through nanoemulsion}

\subsection{Introduction of nanoemulsion synthesis}

Nanoemulsions, similar to microemulsions, are a new class of emulsions having very fine and uniform droplet sizes, typically in the range of 20-200 nm (Solans, Izquierdo et al. 2005). Like microemulsions, nanoemulsions can be either transparent or translucent. Some nanoemulsions appear milky with droplet sizes up to $500 \mathrm{~nm}$. Nanoemulsions, in contrast to microemulsions, are not thermodynamically stable but highly kinetically stable because of their small droplet sizes which make them stable against sedimentation and creaming (Uson, Garcia et al. 2004). One major disadvantage of microemulsions is that they require large amounts of surfactants and co-surfactants (typically over $20 \mathrm{wt} \%$ ) to prepare. This can pose problems for the development of new biomaterials when one considers meeting the paramount requirement of biocompatibility. On the other hand, nanoemulsions offer the possibility of obtaining microemulsion-like dispersions without the need to use high surfactant concentrations or even without the use of any surfactant at all. Nanoemulsions have already found diverse applications in the chemical, cosmetic, pharmaceutical and other industries (Izquierdo, Esquena et al. 2002). 
Nanoemulsions can be prepared by spontaneous low-energy emulsification at constant temperature (Forgiarini, Esquena et al. 2001; Bouchemal, Briancon et al. 2004), the phase inversion temperature (PIT) concept (Izquierdo, Esquena et al. 2004), or by the use of a high shear device such as a high pressure homogenizer (aided by appropriate surfactants and cosurfactants). The latter allows a better control of droplet size and also a large choice of compositions. The polymer nanoprecipitation method firstly described by Fessi et al. (1989) is one of the spontaneous low-energy emulsification techniques for nanoemulsion formulation which has these distinctive advantages: (a) the use of potentially toxic components (such as chlorinated solvents) can be minimized or avoided; and (b) reproducible nanoparticle size with a narrow size distribution can be achieved without an external energy source. The principle of this method resides in the fact that a preformed material can precipitate as nanospheres when a solution in a water-miscible organic solvent (the organic phase) is mixed with water containing surfactants (the aqueous phase). Nanoemulsion has since been considered to be an ideal nano-reactor for the production of metallic nanoparticles such as $\mathrm{GeO}_{2}$ (Kawai, Usui et al. 1999) and CdS (Curri, Leo et al. 2001).

Hydroxyapatite has attracted much attention because it has extensive applications as bone substituting material due to its similarity, both chemical and structural, to the mineral portion of bone (LeGeros and LeGeros 1993). Conventionally, HAp powders are synthesized using various methods based on dry processes such as solid-state reaction (Rao, Roopa et al. 1997) or wet processes such as hydrolysis of calcium phosphates (Ishikawa and Eanes 1993) and the precipitation method (Landi, Tampieri et al. 2000). Microemulsion has been shown to be one of the few techniques which could be used to synthesize fine HAp particles with smaller size and higher surface area (Uota, Arakawa et al. 2005). One major disadvantage of this route, as stated previously, is the required use of large amounts of surfactants and cosurfactants. Nanoemulsions can eliminate this problem. Among various HAp-based bioceramics, carbonated hydroxyapatite (CHAp) is a promising material for bone substitution as it is bioresorbable and also more bioactive in vivo than stoichiometric HAp. CHAp is used mostly as powders and its usefulness depends on the powder properties such as mean particle size, surface area, and morphology. Nanostructured $\mathrm{CHAp}$ particles with a high surface area are desirable for their use in many fields including tissue engineering. The synthesis of nano-CHAp was mostly based on the precipitation reaction developed by Nelson and Featherstone (1982) and studied in details by Barralet et al. (1998; 2000; 2002). Doi et al. have also successfully produced sintered CHAp which can be resorbed by osteoclasts both under in vitro and in vivo conditions, whereas sintered stoichiometric HAp cannot be resorbed (Doi, Koda et al. 1993; Doi, Iwanaga et al. 1999; Hasegawa, Doi et al. 2003). In developing bioactive composites (porous or non-porous) for human tissue repair, apart from particle size and size distribution, the shape of the bioactive and reinforcing particles for the composite is also important (Wang 2003). For theoretical analysis of mechanical behavior of a particulate bioceramic-polymer composite, the bioceramic particles in the composite are normally assumed to have a spherical shape. The nanoemulsion method can produce spherical nanoparticles (Chorny, Fishbein et al. 2002). The synthesis of nano-sized CHAp particles of the preferred spherical shape is a critical step in developing composite scaffolds for bone tissue engineering. The aim of the current study is to investigate the use of oil-in-water $(\mathrm{O} / \mathrm{W})$ nanoemulsion reactor to synthesize CHAp nanospheres with nearly monodispersed size which will be used subsequently for constructing PLLA/CHAp nanocomposite bone tissue engineering scaffolds. 


\subsection{Materials}

The precursors used for synthesizing CHAp nanospheres were analytical grade calcium nitrate 4-hydrate $\left(\mathrm{Ca}\left(\mathrm{NO}_{3}\right)_{2} \cdot 4 \mathrm{H}_{2} \mathrm{O}\right.$, purity $\left.99.0 \%\right)$, di-ammonium hydrogen phosphate $\left(\left(\mathrm{NH}_{4}\right)_{2} \mathrm{HPO}_{4}\right.$, purity $\left.98.5 \%\right)$ and ammonium hydrogen carbonate $\left(\mathrm{NH}_{4} \mathrm{HCO}_{3}\right.$, purity $\left.96.0 \%\right)$ from Uni-Chem ${ }^{\circledR}$ (Orientalab, China). The organic solvent used for making nanoemulsions was analytical grade acetone (AnalaR $\left.{ }^{\circledR}, \mathrm{BDH}, \mathrm{UK}\right)$. Water used throughout the investigation was de-ionized (D. I.) through a reverse osmosis water purification system (Barnstead, Diamond $\left.^{\mathrm{TM}} \mathrm{RO}, \mathrm{USA}\right)$.

\subsection{Synthesis of CHAp through nanoemulsion}

An acetone solution of $\mathrm{Ca}\left(\mathrm{NO}_{3}\right)_{2} \cdot 4 \mathrm{H}_{2} \mathrm{O}$ was mixed with an aqueous solution of $\left(\mathrm{NH}_{4}\right)_{2} \mathrm{HPO}_{4}$ and $\mathrm{NH}_{4} \mathrm{HCO}_{3}$ at a molar ratio of $\mathrm{Ca}^{2+}: \mathrm{PO}_{4}^{3-}: \mathrm{CO}_{3}^{2-}=1.67: 1: 0.5$ using a magnetic stirrer. The aqueous solution was adjusted to $\mathrm{pH} 11$ with sodium hydroxide $(1 \mathrm{M})$ prior to mixing and the mixed solution was stirred for $0.5 \mathrm{~min}$ only. No surfactant was used in all synthesis processes. The resultant CHAp nanoprecipitates in the solution were immediately collected by centrifugation using a Sigma 3-18K refrigerated centrifuge and then washed three times using de-ionized water. Finally, the nanoprecipitates slurry was freeze-dried using a Labconco FreeZone freeze-drying system to obtain dry powder.

When studying the effect of reaction temperature on the microstructure of CHAp, the oil/water volume ratio was fixed at 10/100. The reaction temperatures chosen were 4, 25, 37 and $55{ }^{\circ} \mathrm{C}$ (which is below $56.3^{\circ} \mathrm{C}$, the boiling point of acetone.). When studying the effect of oil/water ratio, the reaction temperature was fixed at $25^{\circ} \mathrm{C}$. The oil/water volume ratios chosen were 5/100, 20/100, 40/100 and 80/100. A small quantity of the dry powder synthesized at $25{ }^{\circ} \mathrm{C}$ was also calcined at $900{ }^{\circ} \mathrm{C}$ for $4 \mathrm{~h}$ in air using a Carbolite HTF 18/8 high temperature furnace.

\subsection{Characterization of CHAp}

\section{X-ray diffraction}

The phase purity and crystallinity of the synthesized apatite powders were examined using X-ray powder diffraction (Raguku Model D/max III diffractometer, Japan). The X-ray beam was nickel-filtered $\mathrm{CuKa}_{1}$ radiation $(\lambda=0.1540 \mathrm{~nm}$, operating at $40 \mathrm{kV}$ and $30 \mathrm{~mA})$. XRD data were collected from $20^{\circ}$ to $40^{\circ}(2 \theta)$ at a scanning rate of $2 \% / \mathrm{min}$.

\section{Fourier transform infrared spectroscopy}

Fourier transform infrared spectroscopy (FTIR, Bruker Vector 33, USA) was performed to determine the presence of functional groups such as $\mathrm{OH}^{-}$groups and $\mathrm{CO}_{3}{ }^{2-}$ groups in the partially substituted apatite. FTIR samples were prepared from 1:150 $\mathrm{CHAp}-\mathrm{KBr}$ mixtures, which were ground and pestle for $15 \mathrm{~min}$ and pressed into pellets using a cold press.

\section{Electron microscopy}

The morphology of the dried nanoprecipitates was examined using a field emission scanning electron microscope (FE-SEM, LEO 1530, Germany) with an energy dispersive Xray spectrometer (EDX, Inca 300, UK). All samples were sputter coated with gold/palladium to increase conductivity prior to SEM examination. A transmission electron microscope (TEM, Philips Tecnai 20, The Netherlands) with an energy dispersive X-ray spectrometry attachment (EDX, Inca 300, UK) was also used to study the morphology, 
surface and fine crystalline structure of the nanoprecipitates. TEM samples were prepared by ultrasonically dispersing the powders in ethanol prior to collection on carbon-coated copper grids. The mean particle size of the nanoprecipitates was estimated from TEM dark field images. Selected area electron diffraction (SAD) patterns were also taken in order to confirm the amorphous or crystalline nature.

\section{Specific surface area measurement}

The specific surface area of the apatite powders was measured using the BET method (Micromeritics, ASAP 2010 N, USA). BET stands for Brunauer, Emmett, and Teller, the three scientists who optimized the theory for measuring surface area (Brunauer, Emmett et al. 1938). The concept of BET theory is an extension of the Langmuir theory, which is a theory for monolayer molecular adsorption, to multilayer adsorption with some hypotheses. BET specific surface area is an important material property of solids which measures the total surface area per unit of mass (with units of $\mathrm{m}^{2} / \mathrm{g}$ ). The adsorption gas used was nitrogen and the values of specific surface area of CHAp nanospheres were calculated from the linear relationship of the BET plot.

\section{Thermogravimetric analysis}

Thermal stability of the as-synthesized CHAp nanospheres was studied using a thermogravimetric analyzer (TGA, model 2050, TA Instruments, USA). The thermogram was recorded from room temperature to $750{ }^{\circ} \mathrm{C}$ at a heating rate of $20^{\circ} \mathrm{C} / \mathrm{min}$ and in a flow of nitrogen gas $(80 \mathrm{~mL} / \mathrm{min})$.

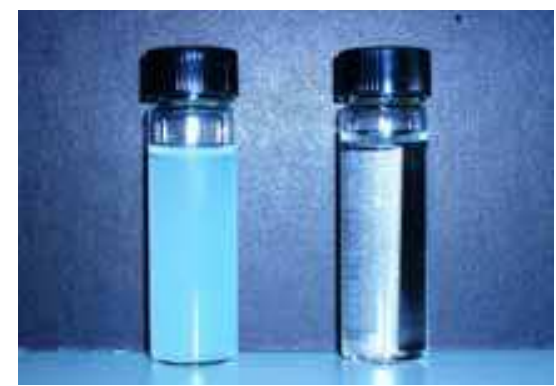

Fig. 2. CHAp nanoemulsion (left) as compared to pure water (right).

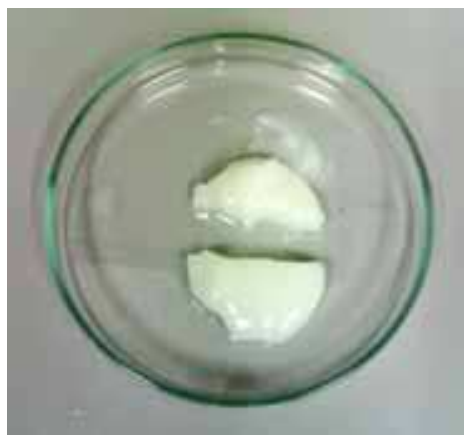

Fig. 3. As-synthesized wet slurry nanoparticles before freeze-drying. 


\subsection{Nanoemulsion and nanoparticles}

As shown in Fig. 2, the nanoemulsions prepared in the current study appeared slightly milky. The tinge of white color increased with increasing nanoprecipitate content. Due to the characteristics of nanoemulsion, the translucent solutions prepared in the nanoemulsion process possessed good stability against sedimentation. Fig. 3 shows the as-synthesized nanoparticles before freeze-drying. The freeze-dried powders could flow easily. It appears that the degree of agglomeration caused by this nanoemulsion and freeze-drying technique is comparatively lower than the wet precipitation and conventional oven drying method which tends to give large agglomerates.

Acetone and ethanol are two common solvents which can dissolve calcium nitrate 4hydrate. Liu et al. (2001) used ethanol as one reaction phase to synthesize HAp in their solgel production route. Ethanol is a protic solvent, and when dissolved with calcium nitrate 4hydrate, ethoxide groups could replace some of the nitrate groups to form $\mathrm{Ca}(\mathrm{OEt})_{y}\left(\mathrm{NO}_{3}\right)_{2-y}$ which could be incorporated finally into the apatite structure. In the current study, acetone was chosen as the oil phase because it is a nonprotic solvent and thus the solvent would not affect the purity of CHAp synthesized. Acetone is a popular industrial solvent because of its volatility and miscibility with water and many organic solvents. It has been widely utilized for tissue dehydration and deoiling of lecithin during its preparation for the food and drug industry (Kuksis, Ravandi et al. 2005). Meanwhile, acetone is present in very small quantities in normal urine and blood and as a product of the breakdown of body fat (Reisman 1998). The plasma concentration of acetone in human was $15 \pm 5 \mu \mathrm{M}$ detected by gas chromatographs (GC) and $75 \pm 21 \mu \mathrm{M}$ detected by high-performance liquid chromatographic measurement (HPLC) (Kalapos 2003). Using acetone as a reaction medium to synthesize apatite may also mimics the natural process of apatite formation. In the nanoprecipitation process for polymers, acetone acts as a common solvent due to its ability to dissolve many biodegradable polymers such as poly(D, L-lactide) (PLA), poly(D, Llactide-co-glycolide) (PLGA) and polycaprolactone (PCL). Combining the CHAp nanoemulsion method reported here with the polymer emulsion solvent evaporation method, acetone can be used as a preparation medium for forming spheres, either in nanometer size or in micrometer size, of bioceramic/biodegradable polymer nanocomposite. The incorporation of nano-sized, amorphous CHAp particles into polymer composite is expected to greatly enhance osteoconductivity for bone tissue engineering application.

The high degree of flowability of freeze-dried, as-synthesized CHAp powders is another distinctive feature. This flow property is important when the CHAp powders are used as raw materials to produce non-porous polymer/bioceramic composites or porous composite scaffolds for human tissue repair. The adequate ability of the powders to flow is required so that the nanospheres could be dispersed sufficiently in the matrix polymer, which could be in the molten state or in the state of polymer solutions, thus enabling the eventual achievement of obtaining high performance (both mechanical and biological) biomaterials.

\subsection{Identification, morphology and structure of CHAp nanoparticles}

Fig. 4 displays the XRD patterns of the nano-sized CHAp particles that were synthesized at different temperatures $\left(4,25,37\right.$ and $\left.55^{\circ} \mathrm{C}\right)$. All diffraction patterns of samples A to D show a very broad hump, indicating a nearly amorphous structure or a very low degree of crystallinity of the nanoparticles. It appears that the reaction temperature had little effect on 
the crystallinity of the particles synthesized through nanoemulsion. For comparison, the XRD pattern of some calcined particles (sample E) is also included in Fig. 4. It exhibits sharp peaks of crystalline HAp (JCPDS 9-432), suggesting that the nanoparticles synthesized at the different temperatures were hydroxyapatite (HAp). Meanwhile, Fig. 5 exhibits the FTIR spectra of the nanoparticles synthesized at $25^{\circ} \mathrm{C}$ before and after calcination at $900^{\circ} \mathrm{C}$, with the bands labeled accordingly for different functional groups. In both spectra, bands for $\mathrm{OH}^{-}$ and $\mathrm{PO}_{4}{ }^{3-}$ groups are present. In the spectrum of the as-synthesized nanoparticles, there is a band at $1647 \mathrm{~cm}^{-1}$, suggesting the existence of a small amount of occluded water. The spectrum also exhibits bands for the $\mathrm{CO}_{3}^{2-}$ group at $870 \mathrm{~cm}^{-1}$ and $1467-1412 \mathrm{~cm}^{-1}$, confirming that the as-synthesized hydroxyapatite is indeed carbonated hydroxyapatite (CHAp). However, these bands disappear after calcination.

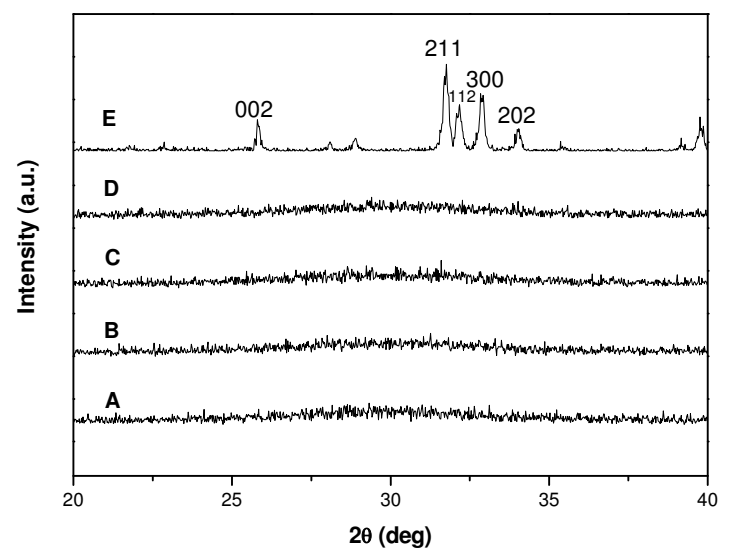

Fig. 4. XRD patterns of CHAp nanoparticles synthesized at: (A) $4^{\circ} \mathrm{C}$, (B) $25^{\circ} \mathrm{C}$, (C) $37^{\circ} \mathrm{C}$, (D) $55^{\circ} \mathrm{C}$, (E) synthesized at $25^{\circ} \mathrm{C}$ and calcined at $900^{\circ} \mathrm{C}$ for 4 hours in air.

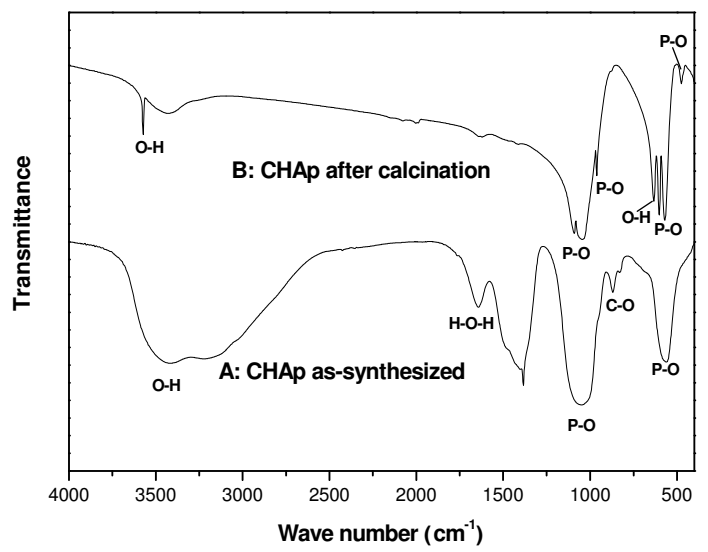

Fig. 5. FTIR spectra of carbonated hydroxyapatite: (A) synthesized at $25^{\circ} \mathrm{C}$, (B) synthesized at $25^{\circ} \mathrm{C}$ and calcined at $900{ }^{\circ} \mathrm{C}$ for 4 hours in air. 
The amorphous structure of the as-synthesized CHAp nanoparticles was probably due to the immediate filtration after nanoprecipitate formation and the subsequent freeze-drying process. Tadic and co-workers (2002) reported similar XRD results when they used high mixing rate and low reaction temperature to form CHAp through a wet precipitation process. There are two processes involved in the formation of apatite in the wet synthesis process: first, precipitation from solution in an amorphous state and second, crystallization within the solid. The proportion of these two processes determines the degree of crystallinity of the apatite obtained. In the current study, the second process was prevented by the fast filtration and freeze-drying processes. Furthermore, carbonate has been known to inhibit HAp crystallization (LeGeros, Trautz et al. 1969). Therefore, the as-synthesized CHAp remained in a generally amorphous or low crystallinity state.

The FTIR spectra shown in Fig. 5 also give some information on the crystallinity of the CHAp particles. Tadic et al. (2002) demonstrated in their IR study that the crystallinity of CHAp would affect the phosphate bands at 590-610 $\mathrm{cm}^{-1}$ and around $1000 \mathrm{~cm}^{-1}$. Broad and unresolved bands indicated a poor crystallinity, whereas sharp and splitting peaks at $565 / 605$ and $1070 / 1150 \mathrm{~cm}^{-1}$ indicated a high crystallinity. In the current study, the absorption bands of $v_{3} \mathrm{PO}_{4}{ }^{3-}$ and $v_{4} \mathrm{PO}_{4}{ }^{3-}$ are broad and the bands of $v_{1} \mathrm{PO}_{4}{ }^{3-}$ and $v_{2} \mathrm{PO}_{4}{ }^{3-}$ are absent for the as-synthesized CHAp (spectrum A in Fig. 5), which indicate the amorphous state of the CHAp. On the issue of $\mathrm{CO}_{3}{ }^{2-}$ substitution in $\mathrm{CHAp}$, the carbonate ions can substitute for both the hydroxyl (A-type CHAp) and phosphate (B-type CHAp) groups in the HAp structure (LeGeros, Trautz et al. 1969). The band at $870 \mathrm{~cm}^{-1}$ is attributed to ${ }_{2} \mathrm{CO}_{3}{ }^{2-}$ substituting for phosphate positions in the HAp lattice (i.e., B-type CHAp). The typical peak of the A-type CHAp at $880 \mathrm{~cm}^{-1}$ (Landi, Celotti et al. 2003) did not appear for the CHAp synthesized in the current study. The double peaks of $v_{2} \mathrm{CO}_{3}{ }^{2-}$ in $1467-1412 \mathrm{~cm}^{-1}$ are broad and unresolved, also indicating the amorphous state of the CHAp. On spectrum $\mathrm{B}$, the absorption bands at $602 / 571$ and $474 \mathrm{~cm}^{-1}$ are attributed to $v_{4} \mathrm{PO}_{4}{ }^{3-}$ and $v_{2} \mathrm{PO}_{4}{ }^{3-}$ of the calcined, crystalline HAp, respectively. Absorptions at 1092/1043 and $962 \mathrm{~cm}^{-1}$ are due to $v_{3} \mathrm{PO}_{4}^{3-}$ and $v_{1} \mathrm{PO}_{4}{ }^{3-}$. The sharp peaks of $\mathrm{O}-\mathrm{H}$ stretching and bending at 3574 and $633 \mathrm{~cm}^{-1}$, respectively, indicate that the material had a high degree of crystallinity. As the calcination temperature used in the current study was high, the peaks of the $\mathrm{CO}_{3}{ }^{2-}$ group totally disappeared from spectrum $\mathrm{B}$, suggesting that the carbonate ion had evolved into $\mathrm{CO}_{2}$ gas during the calcination process.

The carbonate content in bone mineral is around $4-8 \mathrm{wt} \%$ and it has been shown to vary depending on the age of the individual, with an increase of A-type substituted apatite in the old bone (Rey, Renugopalakrishnan et al. 1991). Hence, B-type CHAp is the most abundant apatite in bones of young people. Astala and Stott (2005) used the first principles simulations to study the different carbonate substitution mechanisms in bulk HAp. Their results showed that B-type or $\mathrm{PO}_{4}{ }^{3-}$ substitution is energetically preferred to A-type or $\mathrm{OH}^{-}$ substitution. This can probably explain why most CHAp synthesized, reported in the literature as well as found in the current study, are the B-type substituted HAp. Carbonate in the B site has been found to reduce apatite's crystallinity and size, making it more difficult to characterize the mechanism of carbonate substitution (Barralet, Best et al. 1998). Nelson and Featherstone (1982) studied the precipitation of tri-ammonium orthophosphate and calcium nitrate 4-hydrate. They pointed out that the mechanism of carbonate substitution could be described by:

$$
\mathrm{Ca}_{10-y} \mathrm{Na}_{\mathrm{y}}\left(\mathrm{PO}_{4}\right)_{6-\mathrm{y}}\left(\mathrm{CO}_{3}\right)_{4 y / 3}(\mathrm{OH})_{(2-2 \mathrm{y} / 3)}
$$


In order to determine the value of $\mathrm{y}$, more precise chemical analysis of $\mathrm{CHAp}$, such as ICPAES (Inductively Coupled Plasma - Atomic Emission Spectrometer) would be needed for the $\mathrm{Ca}, \mathrm{Na}, \mathrm{P}$ and $\mathrm{C}$ wt $\%$.

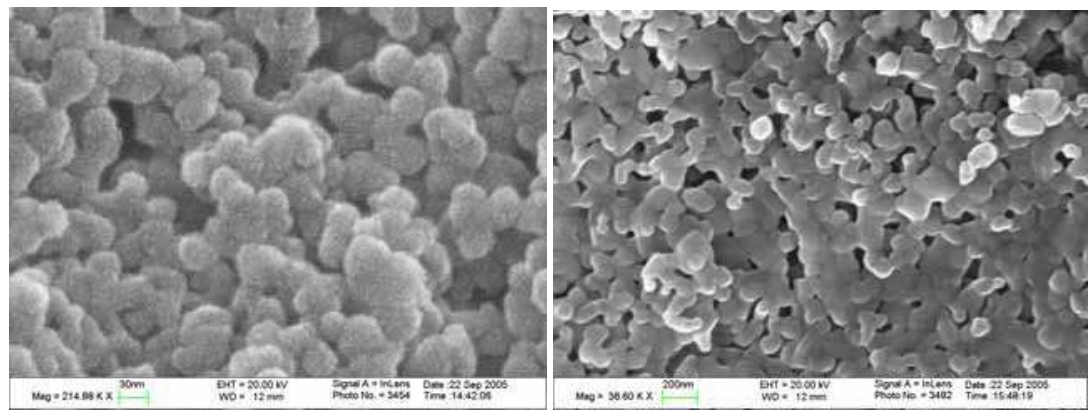

Fig. 6. Morphology of CHAp nanospheres synthesized at $25^{\circ} \mathrm{C}$ with an oil/water ratio $=10 / 100$ (left) and calcined at $900{ }^{\circ} \mathrm{C}$ for 4 hours in air (right).

Fig. 6 shows the FE-SEM micrographs of the as-synthesized and calcined CHAp powders respectively. The as-synthesized CHAp powder consists of tiny agglomerates of nanoparticles $(\sim 20 \mathrm{~nm}$ in diameter) in the freeze-dried state whereas the calcined CHAp powder has coarsened to particles in the micrometer range. Furthermore, the calcined CHAp particles have undergone necking as a result of the high-temperature calcination process. This observation is in agreement with the BET specific surface area measurements of the CHAp powders. The original specific surface area of the as-synthesized nanoparticles is $43.67 \pm 0.03 \mathrm{~m}^{2} / \mathrm{g}$. It drops to $13.24 \pm 0.09 \mathrm{~m}^{2} / \mathrm{g}$ after calcination at $900{ }^{\circ} \mathrm{C}$. The large reduction in surface area likely affects the properties of the CHAp particles.

Since there was no surfactant used in the nanoemulsion processes in the current study; therefore, the specific surface area of the CHAp nanoparticles is not as high as surfactantaided systems (Bose and Saha 2003). The calcination temperature selected in the current study was high and hence caused large reductions in the specific surface area of the CHAp particles. The purpose of using such a high calcination temperature was to crystallize the nanoparticles in order to demonstrate that the as-synthesized nanoparticles through the nanoemulsion method were actually apatite. However, in post-synthesis treatment of the precipitated CHAp nanospheres for their actual use as a biomaterial on its own or incorporated into other materials, if calcination is required, the calcination temperature should be kept as low as possible in order not to lose the $\mathrm{CO}_{3}{ }^{2-}$ functional group nor to reduce the characteristic high surface area of the nanoparticles. Calcined apatite crystals on a nanoscale have been difficult to obtain because the precursor particles will be sintered randomly into micro-sized agglomerates consisting of polycrystals (Barralet, Best et al. 2000; Landi, Tampieri et al. 2000; Okada and Furuzono 2007).

Fig. 7 shows the CHAp nanospheres synthesized at different reaction temperatures with an oil/water ratio of 10/100. The primary particles are similar to those synthesized at room temperature, i.e. generally spherical in shape and about $20 \mathrm{~nm}$ in diameter. The assynthesized CHAp nanospheres also tend to form tiny agglomerates in the freeze-dried state. The overall results suggest that the microstructure of the CHAp nanoparticles did not change significantly within the range of reaction temperatures. Therefore, room temperature was chosen to be the reaction temperature in the subsequent studies. 


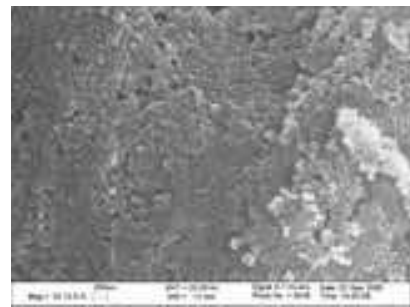

(a)

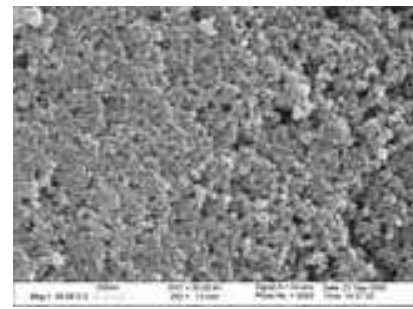

(b)

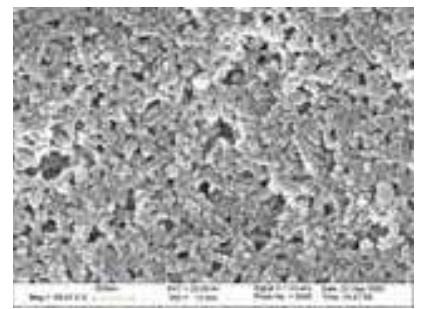

(c)

Fig. 7. SEM micrographs of CHAp nanospheres synthesized with an oil/water ratio=10/100 and synthesis temperatures at: (a) $4{ }^{\circ} \mathrm{C}$, (b) $37^{\circ} \mathrm{C}$, (c) $55^{\circ} \mathrm{C}$.

Fig. 8 shows the CHAp synthesized at room temperature but with different oil/water ratios. Apparently, CHAp nanospheres could only be obtained in low acetone/water ratios and higher oil/water ratios would cause the CHAp particles to agglomerate excessively. Based on the result, the oil/water volume ratio for subsequent studies was chosen to be 10/100.

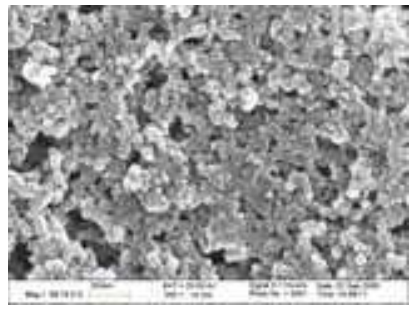

(a)

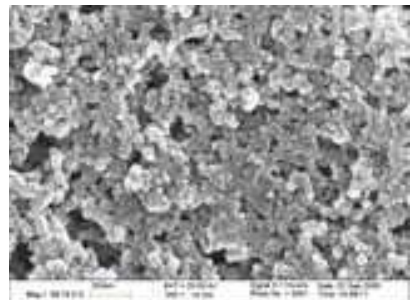

(b)

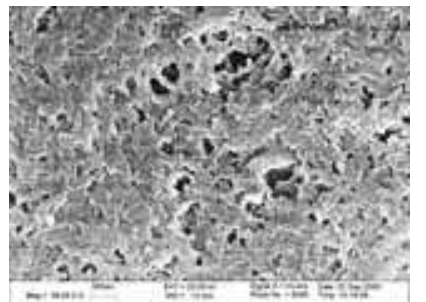

(c)

Fig. 8. SEM micrographs of CHAp synthesized at $25^{\circ} \mathrm{C}$ with oil/water ratios of: (a) 5/100, (b) 20/100, (c) 40/100.

It has been reported that in the wet synthesis processes, HAp mostly forms needle-shaped crystallites that have preferential growth in the (002) direction (Puajindanetr, Best et al. 1994; Bose and Saha 2003). In the current study, the CHAp nanoparticles produced were spherical. This can be attributed to the fact that the precipitates were confined in nano-sized emulsion droplets. LeGeros and co-workers demonstrated that the $\mathrm{CO}_{3}{ }^{2-}$ in substituted HAp caused changes in the size and shape of apatite crystal: from acicular crystals to rods and then to equiaxed crystals with an increasing carbonate content from 2.5 to $17.25 \mathrm{wt} \%$ (LeGeros and LeGeros 1993). In the current study, the theoretical carbonate content was 12.8 $\mathrm{wt} \%$ as calculated from the chemical formula $\mathrm{Ca}_{10}\left(\mathrm{PO}_{4}\right)_{4}\left(\mathrm{CO}_{3}\right)_{2}(\mathrm{OH})_{2}$. The formation of spherical CHAp nanoparticles is due to two reasons: one is the relatively high carbonate content in the CHAp structure, which agrees with LeGeros' observation; the other is the nanoemulsion reactor used in the current synthesis process which is caused by the Ouzo effect (Ganachaud and Katz 2005). The Ouzo effect is a spontaneous emulsification, which causes the formation of acetone/water nanoemulsion. The mechanism of the Ouzo effect is a liquid-liquid nucleation process which arises when mixing with water, the water miscible oil becomes greatly supersaturated, resulting in the nucleation of oil droplets. Following this, the oil immediately begins to diffuse to the nearest droplet so that the level of supersaturation decreases and no further nucleation of droplets occurs. The final metastable emulsion is an ideal nano-reactor to form either ceramic or polymer nanospheres. The 
formation of CHAp nanospheres with a low oil/water ratio only can be explained by the Ouzo effect too. When using a higher acetone/water ratio to prepare the nanoemulsion, the acetone droplets tend to become larger in order to reduce the level of supersaturation. Sometimes these acetone droplets can become interconnected, forming a continuous CHAp network such as shown in Fig. 8 (b) and (c).

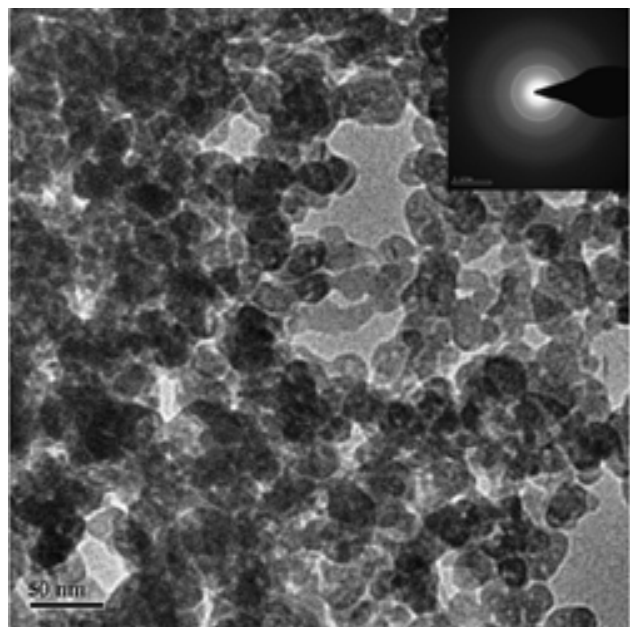

Fig. 9. TEM image and SAD pattern (inset) of the CHAp powder synthesized at $25^{\circ} \mathrm{C}$.

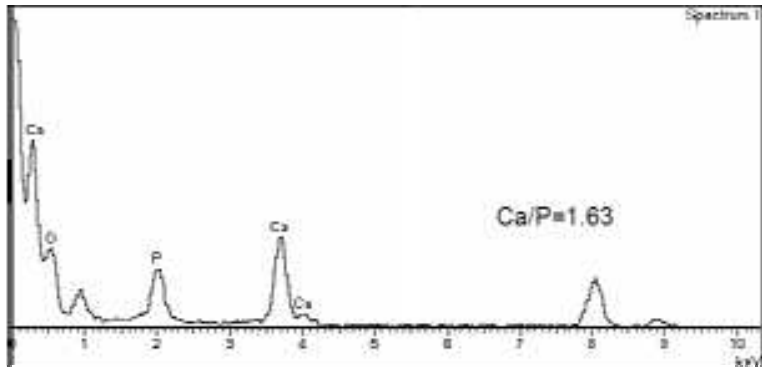

Fig. 10. EDX spectrum of the CHAp powder synthesized at $25^{\circ} \mathrm{C}$.

Fig. 9 is a TEM micrograph, together with the SAD pattern, of the as-synthesized CHAp nanoparticles. Clearly, they are spherical in shape and their sizes are in the range of 10-30 nm. Image analysis of TEM micrographs using the Image ${ }^{\circledR}$ software reveals that these CHAp nanospheres are $16.8 \pm 2.6 \mathrm{~nm}$ in diameter. The SAD pattern shown on the top right corner is typical of those obtained from the nanosphere agglomerates. It exhibits muchdiffused electron diffraction rings, confirming a low degree of crystallinity of the assynthesized CHAp nanoparticles, and which agrees well with the XRD results in Fig. 4. However, the crystallization process could not be totally stopped, and hence the SAD patterns do indicate some degree of crystallinity of the CHAp nanoparticle. Fig. 10 shows the EDX spectrum of the as-synthesized CHAp. The $\mathrm{Ca} / \mathrm{P}$ ratio determined from this spectrum is 1.63 , which suggests that the CHAp is calcium-deficient. 


\subsection{Thermal property of CHAp nanospheres}

The thermal stability of CHAp powder is important for its biological application. Heattreatment experiments of CHAp were performed in various gas atmospheres, including nitrogen, carbon dioxide, air, water vapor and wet oxygen (Barinov, Rau et al. 2006). The gas atmosphere was shown to affect the CHAp decomposition significantly. CHAp decomposition occurred at temperature as low as $750^{\circ} \mathrm{C}$ when heat-treated in an air atmosphere. However, when sintered in a wet carbon dioxide atmosphere, the CHAp did not show any evidence of decomposition at temperature up to $1300{ }^{\circ} \mathrm{C}$ (Barralet, Best et al. 2000; Barralet, Knowles et al. 2002). Besides the effect of heat-treatment atmospheres, the thermal stability of CHAp will also depend on the synthesis technique and route.

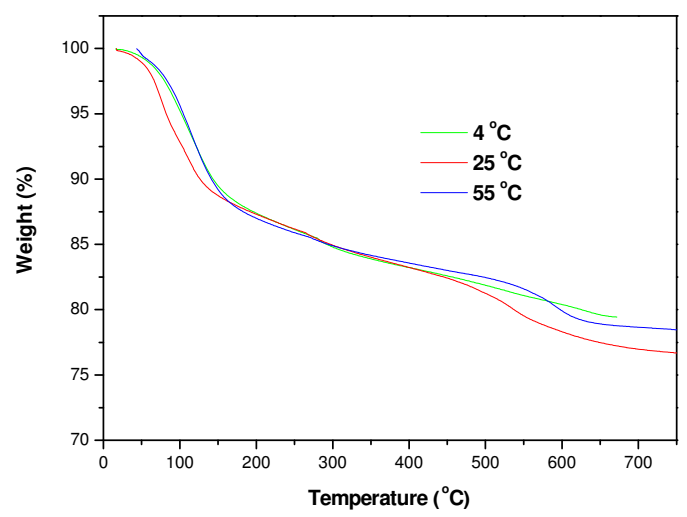

Fig. 11. TGA traces of CHAp nanospheres synthesized at different temperatures.

Fig. 11 shows the TGA traces of CHAp synthesized at different temperatures in terms of weight loss as a function of temperature. In general, there is a major first phase weight loss in the temperature range around $100{ }^{\circ} \mathrm{C}$. The second phase of weight loss occurs more gradually between 150 to $550{ }^{\circ} \mathrm{C}$. After that, another more rapid weight loss is observed between 550 and $650{ }^{\circ} \mathrm{C}$. The weight loss near $100^{\circ} \mathrm{C}$ is likely due to the evaporation of surface absorbed and lattice (occluded) water molecules. Such weight loss accounts for about $12 \mathrm{wt} \%$ of the CHAp synthesized at 4,25 and $55^{\circ} \mathrm{C}$, indicating a highly absorbent nature of the CHAp nanospheres. The phenomenon can be attributed to the high specific surface area of the nanospheres. In fact, this high water content was also detected in the FTIR spectrum of the as-synthesized CHAp (see O-H band at around $3500 \mathrm{~cm}^{-1}$ in Fig. 5). The second phase weight loss up to about $550{ }^{\circ} \mathrm{C}$ is probably caused by the condensation reaction of $\mathrm{HPO}_{4}{ }^{2-}$ ion in the following reactions:

$$
\begin{gathered}
\mathrm{PO}_{4}^{3-}+\mathrm{H}_{2} \mathrm{O} \rightarrow \mathrm{HPO}_{4}^{2-}+\mathrm{OH}^{-} \\
2 \mathrm{HPO}_{4}^{2-}+2 \mathrm{CO}_{3}^{2-} \rightarrow 2 \mathrm{PO}_{4}^{3-}+\mathrm{H}_{2} \mathrm{O} \uparrow+2 \mathrm{CO}_{2} \uparrow
\end{gathered}
$$

The condensation reaction of $\mathrm{HPO}_{4}{ }^{2-}$ occurs through the proton transfer to labile carbonate ion and the bicarbonate ion $\left(\mathrm{HCO}_{3}{ }^{-}\right)$decomposition at low temperatures (Landi, Tampieri et al. 2005). Further decrease of TGA traces after $550{ }^{\circ} \mathrm{C}$ mainly corresponds to the decomposition of carbonate ion substituted for phosphate groups (B-type substitution) 
which is confirmed by the $\mathrm{CO}_{2}$ peak from FTIR on-lined with TGA (Barinov, Rau et al. 2006). There may be a small amount of water released from $\mathrm{HPO}_{4}{ }^{2-}$ reaction, such as (Guo and Xiao 2006)

$$
\begin{gathered}
2 \mathrm{HPO}_{4}^{2-} \rightarrow \mathrm{P}_{2} \mathrm{O}_{7}^{4-}+\mathrm{H}_{2} \mathrm{O} \uparrow \\
\mathrm{P}_{2} \mathrm{O}_{7}^{4-}+2 \mathrm{OH}^{-} \rightarrow 2 \mathrm{PO}_{4}^{3-}+\mathrm{H}_{2} \mathrm{O} \uparrow
\end{gathered}
$$

Furthermore, the TGA traces beyond $500{ }^{\circ} \mathrm{C}$ are more wide spread. One possible explanation is that the amounts of carbonate substituted in the samples are different, causing the decomposition rate to change. This indicates that synthesis temperature will affect the amount of substituted carbonate and hence the thermal stability of the CHAp nanospheres at relatively high temperatures. In order to fully understand the thermal characteristics of the CHAp nanospheres, STA (simultaneous thermal analysis) or DTA (differential thermal analysis) on-lined with FTIR would be required and the studying temperature should up to $1400{ }^{\circ} \mathrm{C}$ if possible.

\section{Fabrication and evaluation of poly(L-lactide) microspheres and poly(L- lactide)/carbonated hydroxyapatite nanocomposite microspheres}

\subsection{Introduction of nanocomposite microspheres}

Bone itself is a naturally occurred inorganic-organic nanocomposite. Therefore, the new generation of biomaterials for bone tissue engineering should include hybrid materials that combine the strength and stiffness of bioactive inorganic fillers with the flexibility and toughness of biocompatible organic matrices. The aim of this part of research is to fabricate and characterize PLLA microspheres and PLLA/CHAp nanocomposite microspheres which will be used in building bone tissue engineering scaffolds by selective laser sintering. CHAp more closely resembles the mineral component of bone than stoichiometric HAp and providing PLLA microspheres with bioactivity or osteoconductivity. PLLA is an FDAapproved, biocompatible and biodegradable polymer which is used in many biomedical applications. But the degradation of pure PLLA implants in the human body is known to produce intermediate acidic products that often lead to the bacteria-free inflammatory responses. CHAp in the PLLA composite could help to buffer such by-products (Agrawal and Athanasiou 1997; Yang, Cui et al. 2006).

Fabrication of desirable micro-sized polymer powders is a critical step for the SLS process in building TE scaffolds with appropriate macro-porosity and surface morphology. Biodegradable microspheres have been prepared by various fabrication methods based on the modifications of three basic techniques: emulsion solvent extraction/evaporation, phase separation (coacervation) and spray-drying (Freitas, Merkle et al. 2005) and widely used in controlled drug delivery systems. Phase separation is frequently impaired by residual organic solvents and coacervation agents found in the microspheres and this method is not suitable for producing small size microspheres (Thomasin, Johansen et al. 1996). Spraydrying is relatively simple but needs special equipment. Moreover, it is difficult to control the size of microsphere and small batches yields are moderate ( $\mathrm{Mu}$ and Feng 2001). The main disadvantage of spray-drying is its cost, in terms of both equipment and operation ( $\operatorname{Re}$ 2006). Emulsion solvent extraction/evaporation neither requires high temperatures nor phase separation inducing agents, so it is usually favored at lab scale or small scale. Controlled microsphere sizes in the nano to micrometer range can be achieved, but careful 
selection of preparation conditions is needed to obtain desired size and size distribution with a low residual solvent content (Freitas, Merkle et al. 2005).

Polymer microsphere preparation by emulsion solvent extraction/evaporation used for controlled delivery of drugs basically consists of four major steps: (i) dissolution or suspension of the bioactive compound either in water phase or in oil phase; (ii) emulsification of oil phase with water phase; (iii) extraction of the solvent from oil phase by water phase which resulting the solidified polymer microspheres; (iv) harvesting and drying the polymer microspheres. As steps (i) - (iii) are all conducted in beakers, this microspheres fabrication technique can be also called as "beaker method" (Siepmann and Siepmann 2006). The major advantage of this "beaker method" is that it does not need high cost equipment. The disadvantages are the problem for the scale-up and the broad size distribution of the microspheres.

\subsection{Materials}

The PLLA used was 100L 1A with an intrinsic viscosity of $1.9 \mathrm{dL} / \mathrm{g}$ (Lakeshore Biomaterials, Birmingham, AL, USA). It was supplied in the form of macro-sized pellets, $1 \mathrm{~mm}$ in diameter and $3 \mathrm{~mm}$ in length, for conventional extrusion and moulding processes. The emulsifier used was poly(vinyl alcohol) which was cold water soluble and with an average molecular weight of 30,000-70,000 (PVA, m. p. $=200{ }^{\circ} \mathrm{C}$, Sigma-Aldrich, USA). Dichloromethane or methylene dichloride (DCM, Uni-Chem ${ }^{\circledR}$, Orientalab, China) was used as the organic solvent to dissolve PLLA. The analytic reagent (A. R.) grade DCM was used for initial study of the preparation condition of PLLA microspheres, while the chemically pure (C. P.) grade was used for the batch production of large amount of PLLA microspheres for the economical concern.

\subsection{Preparation of PLLA microspheres}

PLLA microspheres were prepared using a normal oil-in-water $(\mathrm{O} / \mathrm{W})$ emulsion solvent evaporation technique. In brief, the PLLA was dissolved in DCM to form a solution first and then rapidly added to aqueous PVA solution and stirred for sometime to allow the solvent to evaporate. The hardened microspheres were centrifuged, washed three times with D. I. water and lyophilized to get dry powder. The powder was stored in the drying cabinet before use. The effects of three preparation conditions, i.e. polymer concentration, emulsifier concentration and mixing speed on the size and size distribution of PLLA microspheres were examined.

\subsection{Preparation of PLLA/CHAp nanocomposite microspheres}

The PLLA/CHAp nanocomposite microspheres were prepared using a solid-in-oil-in-water (S/O/W) emulsion solvent evaporation method. Briefly, the CHAp nanospheres were dispersed in the PLLA-dichloromethane solution by ultrasonification (Barnstead Lab-Line ultrasonic cleaner, USA) and homogenization (Ultra-Turrax ${ }^{\circledR}$ T25 basic, IKA, Germany) to form an S/O nanosuspension. The nanosuspension was mixed with $1 \mathrm{wt} \%$ PVA solution to form $\mathrm{S} / \mathrm{O} / \mathrm{W}$ emulsion. The resultant $\mathrm{S} / \mathrm{O} / \mathrm{W}$ emulsion was magnetic stirred overnight at $800 \mathrm{rpm}$ and then filtered, washed three times with de-ionized water, and freeze-dried to yield a white PLLA/CHAp biocomposite powder. Different contents of CHAp, ranging from 2.5 to $50 \mathrm{wt} \%$, were used to prepare the composite microspheres. Finally, biocomposite microspheres of $10 \mathrm{wt} \%$ CHAp in PLLA were used in the SLS process. 


\subsection{PLLA microspheres}

\subsubsection{Effect of PLLA concentration}

Fig. 12 shows the effect of PLLA concentration on the mean particle size of the PLLA microspheres. It is obvious that the mean particle size increases with increasing PLLA concentration. Similar observations were made by other researchers. Freitas and Marchetti (2005) investigated the influence of this factor, covering a range of PLA concentrations between $0.05 \%$ and $0.15 \%(\mathrm{w} / \mathrm{v})$ in the organic phase. They found that the particle size increased with increasing polymer concentrations, which was in agreement with other contribution (Jeffery, Davis et al. 1991). The phenomenon can be explained by the emulsification efficiency of PVA. The same concentration of PVA would only stabilize larger emulsion droplets with the increasing of PLLA content.

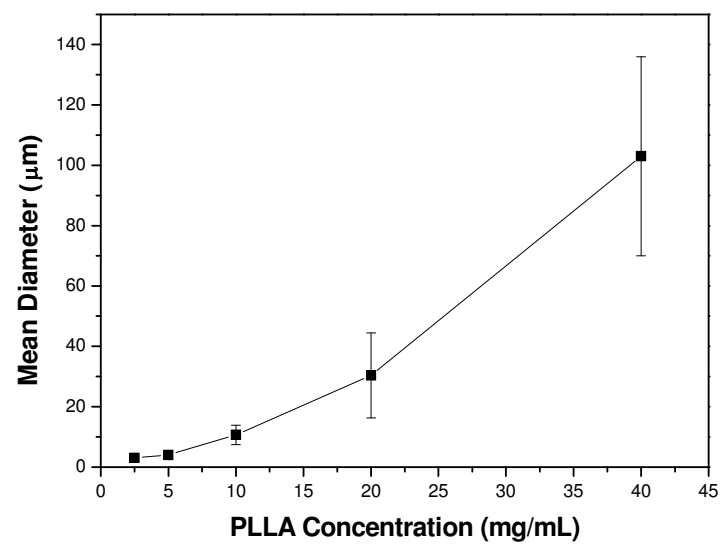

Fig. 12. Effect of PLLA concentration on mean particle size of PLLA microspheres.

\subsubsection{Effect of PVA concentration}

The effect of PVA concentration on the mean particle size of the PLLA microspheres is shown in Fig. 13. Compared with PLLA concentration, PVA concentration only has limited effect on the mean particle size of the PLLA microspheres, which varies between 17 and 46 $\mu \mathrm{m}$. Finally, $1 \mathrm{wt} \%$ PVA was used for scale-up production of PLLA microspheres, by that most of the particles obtained were between 15 and $45 \mu \mathrm{m}$ and suitable for the SLS process. The role of emulsifier is to form a protecting thin layer around the oil drops, with the aim to reduce the coagulation and to stabilize the emulsion. The most commonly employed emulsifiers in emulsion solvent evaporation technique are hydrophilic polymers and anionic/cationic surfactants. PVA is the most widely used emulsifier; however polyvinylpyrrolidone (PVP), alginate, gelatin, methyl cellulose or lecithin can also be employed. Recent studies suggest that a residual of the emulsifier always linked to the particles despite of the washing and purification processes (Shakesheff, Evora et al. 1997) because PVA forms an interconnected network with the polymer microsphere at the surface (Sahoo, Panyam et al. 2002). Freitas and Marchetti (2005) have observed that the amount of surfactant may affect the microspheres properties. They added $1.3 \%$ and $8 \%$ of PVA to the aqueous solution and determined that the lower and higher concentrations of surfactant 
promoted the coagulation of the particles. Thus, the adequate amount of PVA proposed by these authors was 3\%. Sahoo et al. (2002) reported that the amount of residual PVA that remains associated with the PLGA nanoparticles can be controlled by altering the PVA concentration or the type of organic solvent used in the emulsion formation, and is an important factor that influences the cellular uptake of nanoparticles.

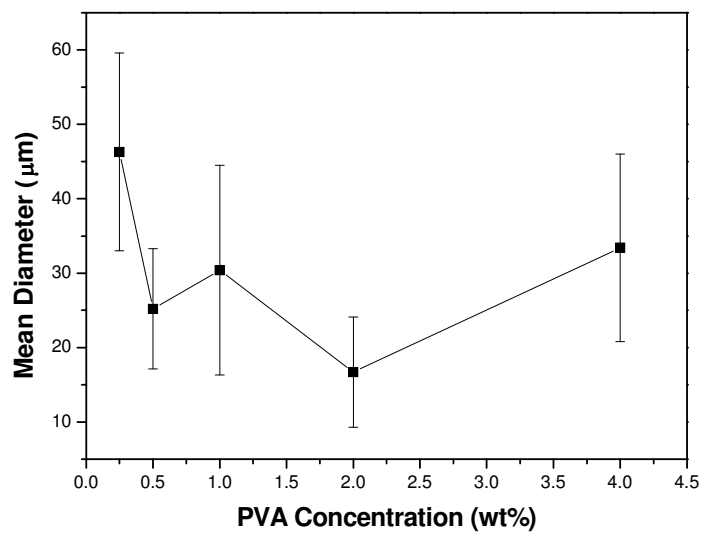

Fig. 13. Effect of PVA concentration on mean particle size of PLLA microspheres.

In this study, the determination of appropriate PVA concentration is based on two considerations: one is the size and size distribution of microspheres which would be suitable for SLS process; the other is the residual amount of PVA on the microsphere surface. The residual PVA can also alter the surface hydrophobicity of PLLA and PLLA/CHAp microspheres since PVA serves as a surfactant which has both the hydrophobic and hydrophilic segments. Imparting more hydrophilicity on PLLA and PLLA/CHAp microsphere surface may benefit the cell attachment. The mechanism of PVA binding has been proposed to be due to the interpenetration of PVA and PLLA molecules during microspheres formulation (Boury, Ivanova et al. 1995; Sahoo, Panyam et al. 2002). The hydrophobic segments of PVA penetrate into the oil phase and remain entrapped into the polymeric matrix of the microspheres. The binding of PVA on the particle surface likely happens when the organic solvent diffuses from the interface of emulsion droplets with water phase. Partially hydrolyzed PVA is a block copolymer of poly(vinyl acetate) and poly(vinyl alcohol). The hydrophobic poly(vinyl acetate) part serves as an anchor polymer at the oil phase for binding to the surface of PLLA during the formulation. Thus, the higher PVA concentration of the continuous phase could lead to an increase in PVA molecule density at the $\mathrm{O} / \mathrm{W}$ interface of the emulsion droplet, which might increase the amount of PVA on the droplet surface. Previous reports showed that the size of PLGA microspheres decreases with increasing PVA concentration in the external aqueous phase (Zambaux, Bonneaux et al. 1998; Lee, Oh et al. 1999; Sahoo, Panyam et al. 2002). In the current study; however, this trend was not clear and it might be due to the high inherent viscosity (1.6 $\mathrm{dL} / \mathrm{g}$ ) and semicrystalline nature of the PLLA. The inherent viscosity of PLGA usually lies between 0.15 and $0.8 \mathrm{dL} / \mathrm{g}$ (lakeshorebio.com). Furthermore, PLGA are amorphous copolymers which make it easier for PVA to break them into emulsion droplets than the semicrystalline PLLA. 


\subsubsection{Effect of mixing speed}

The effect of mixing speed on the mean particle size of PLLA microspheres is shown in Fig. 14. It can be seen that the mixing speed did not affect the mean size of PLLA microspheres significantly. However, the higher speed seemed to give a broader size distribution.

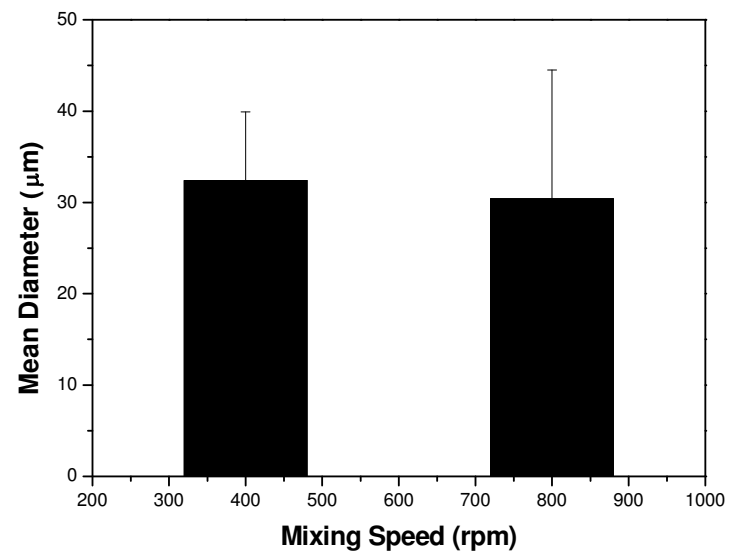

Fig. 14. Effect of mixing speed on mean particle size of PLLA microspheres.

\subsubsection{Effect of residual solvent}

Dichloromethane (DCM) was used as the oil phase in this study because of the ability to dissolve large amounts of PLLA as well as its low solubility in water $(2.0 \mathrm{wt} \%, \mathrm{w} / \mathrm{v})$ and low boiling point $\left(39.8^{\circ} \mathrm{C}\right)$, which is compatible with the evaporation step (Tewes, Boury et al. 2006). DCM may be retained in the PLLA microspheres as a residual impurity. DCM belongs to the Class 2 solvents according to the International Conference on Harmonization (ICH) because they are suspected of carcinogenicity as well as neurotoxicity and teratogenicity. The maximum limit for DCM imposed by the 2002 edition of the United States Pharmacopeia (USP) and the guidelines of the ICH is $600 \mathrm{ppm}$ while the maximum limit for chloroform is $60 \mathrm{ppm}$ (USP25-NF20 2002). DCM is one of the less harmful of the chlorocarbons based on above data. Benoit et al. (1986) measured residual DCM content in progesterone-loaded microparticles prepared by the emulsification solvent evaporation technique. They found that vacuum drying led to a reduction of the solvent content from 18,000 to $360 \mathrm{ppm}$ for PLA microparticles. Bitz and Doelker (1996) showed that the residual amount of DCM in dried PLLA microspheres is $4.2 \pm 1.0 \mathrm{ppm}$ by the $\mathrm{W} / \mathrm{O} / \mathrm{W}$ emulsion technique. These results indicate that applying long time of vacuum drying process will dramatically reduce the amount of residual DCM in polymer microspheres and fulfill the guidelines of the Pharmacopeia.

For a typical emulsion solvent evaporation/extraction process, the polymer/ organic solvent dispersed oily phase is emulsified in an aqueous phase, in order to make an $\mathrm{O} / \mathrm{W}$ emulsion. During mechanical stirring, the organic solvent in emulsion droplets diffuses to the aqueous phase and evaporates to air or extracts to the quenching medium, thereby leading to the formation of microspheres. Dichloromethane, having high volatility and water immiscibility, is the most frequently used dispersed solvent for the emulsion process. In general, less solubility of the organic solvent in water results in a more stable emulsion 


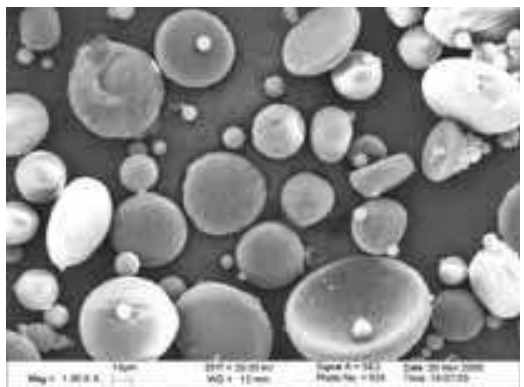

(a)

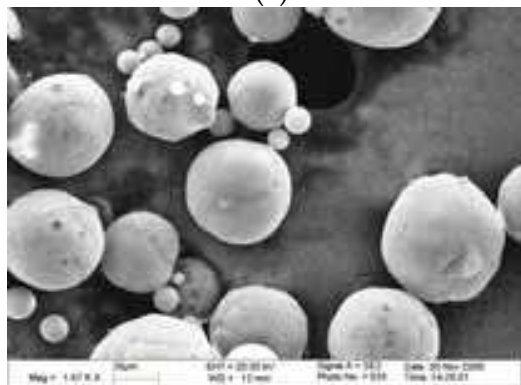

(c)

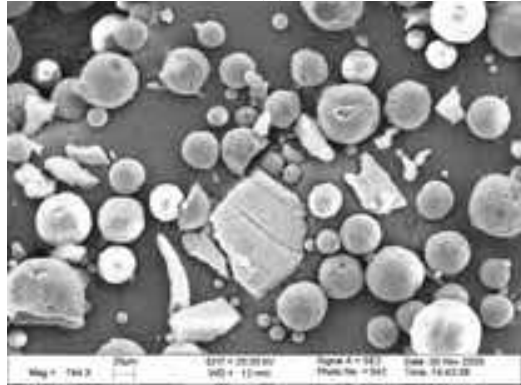

(e)

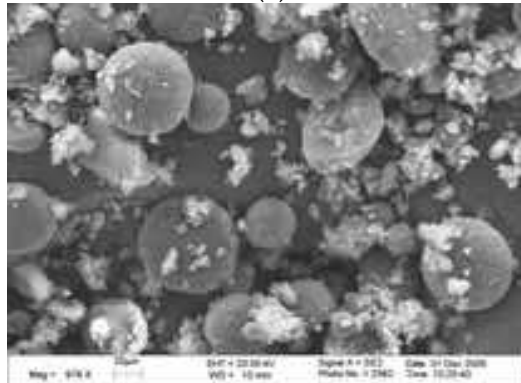

(g)

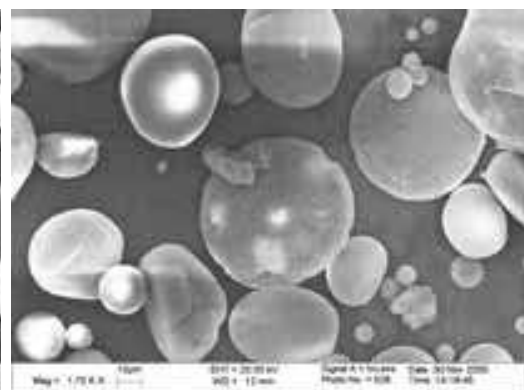

(b)

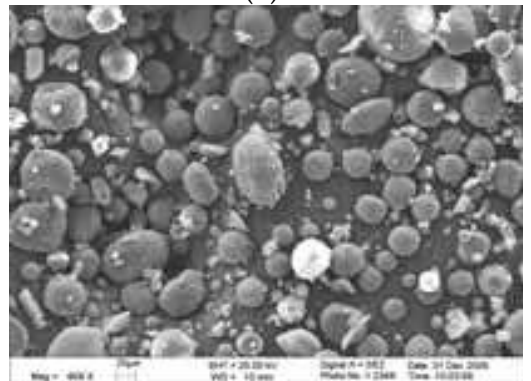

(d)

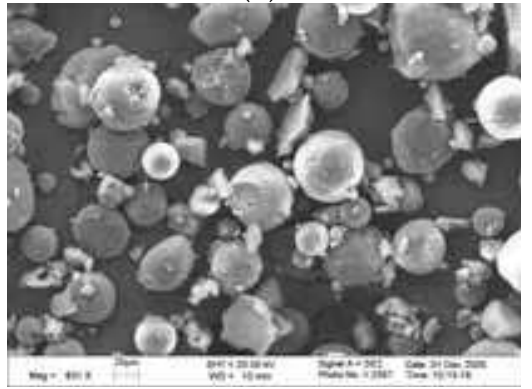

(f)

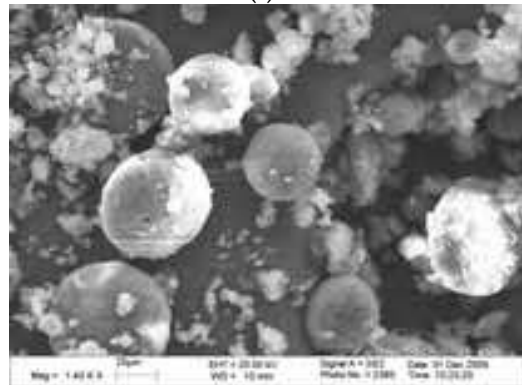

(h)

Fig. 15. SEM images of PLLA/CHAp biocomposite microspheres with different CHAp nanosphere content: (a) $2.5 \mathrm{wt} \%$, (b) $5 \mathrm{wt} \%$, (c) $10 \mathrm{wt} \%$, (d) $15 \mathrm{wt} \%$, (e) $20 \mathrm{wt} \%$ (f) $30 \mathrm{wt} \%$, (g) $40 \mathrm{wt} \%$ and (h) $50 \mathrm{wt} \%$. 
that leads to spherical particles with nonporous surface and a better size distribution (Freitas and Marchetti 2005). There are two processes of solvent removal which influence microsphere size and morphology. One is the evaporation process in which the emulsion is maintained at reduced (such as in rotary evaporator) or atmospheric pressure under stirring. Another is the extraction process in which the emulsion is transferred into a large volume of water (with or without surfactant) or another quench medium, where the solvent diffuses out. The similarity for these two processes is in that the solvent must first diffuse out. So the rate of solvent removal influences the properties of the microspheres. Rapid solvent removal leads to the formation of nano-pores on the surface of microspheres and decreases the crystallinity of polymer. The extraction process is fast and generally less than $30 \mathrm{~min}$ which forming the porous and more amorphous microspheres (Tewes, Boury et al. 2006). However, the extraction process needs large amount of quench medium which makes it unpractical in the large-scale production.

\subsection{PLLA/CHAp nanocomposite microspheres}

\subsubsection{Effect of CHAp content}

Despite changes in the CHAp content, the biocomposite microspheres exhibited a generally constant range of particle sizes between 5 and $30 \mu \mathrm{m}$, Fig. 15. Particles of these sizes are suitable for selective laser sintering to produce porous scaffolds for bone tissue engineering. When the CHAp nanosphere content was less than $10 \mathrm{wt} \%$, Fig. 15 (a)-(c), no bare CHAp nanospheres were observed among the composite microspheres and the CHAp nanospheres were believed to be fully encapsulated within the microspheres to form a nanocomposite structure. When the CHAp nanosphere content was above 15 wt \%, Fig. 15 (d), a small amount of CHAp agglomerates appeared among the composite microspheres. When the CHAp content exceeded $20 \mathrm{wt} \%$, Fig. 15 (e)-(h), substantial amounts of CHAp agglomerates were seen among the PLLA/CHAp microspheres and major $\mathrm{Ca}$ and $\mathrm{P}$ peaks could be detected from these agglomerates by EDX.

\subsubsection{Internal structure}

In order to study the distribution of CHAp nanospheres inside some nanocomposite microspheres, sectional views of the PLLA/CHAp nanocomposite microspheres were observed by different methods. First, some microspheres were embedded in epoxy resin and then sectioned with a microtome. The difficulty of this method was the determination of thickness needed to be removed from the microspheres. After some careful trials, it yielded some satisfactory results. Fig. 16 shows a sectional view of a PLLA/CHAp nanocomposite microsphere. It can be seen that large amount of CHAp nanospheres are encapsulated within the microsphere.

Second, FIB-milling was used to examine the internal structure. FIB-milling is an advanced technology which can remove material at extremely precise location. As stated earlier, polymer and apatite are non-conductive materials. So after milling, the samples need to be coated before the SEM examination. The re-location of the milled sample may be a problem. The SEM image was taken immediately after FIB-milling and it is not so clear due to the low conductivity of PLLA and CHAp. Fig. 17 shows an improved SEM image of the FIB-milled PLLA/CHAp nanocomposite microsphere after sputtering coating with Au. The CHAp nanospheres are generally well distributed both on and inside the microsphere, forming a nanocomposite structure. The rough surface of the nanocomposite microsphere likely facilitates cell attachment. 


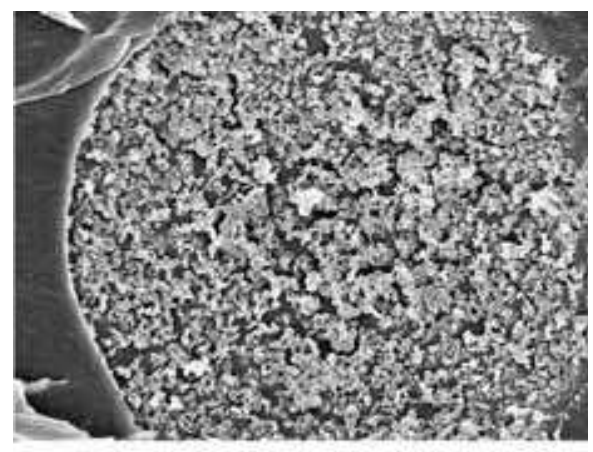

Fig. 16. Cross-sectional view of a PLLA/CHAp nanocomposite microsphere.

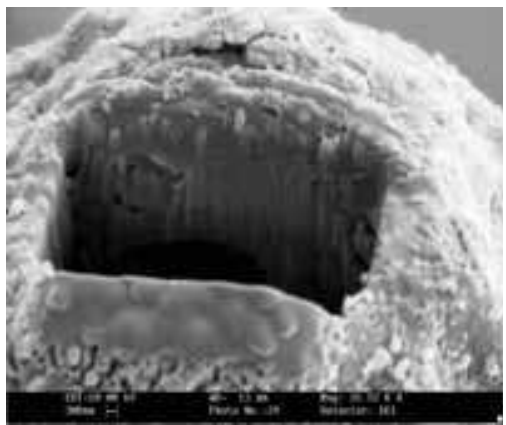

Fig. 17. SEM image of an FIB-milled PLLA/CHAp nanocomposite microsphere.

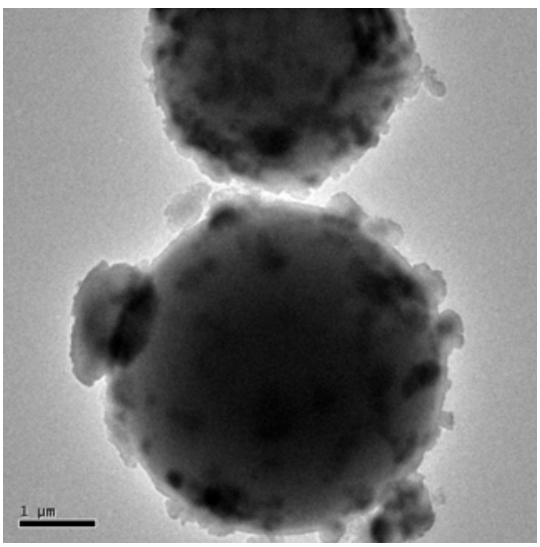

Fig. 18. TEM image of PLLA/CHAp nanocomposite microspheres.

The third method was using TEM to view through the nanocomposite structure. However, TEM uses a very high voltage electron beam so it may damage the polymer matrix and move the CHAp particles. Also, the size of the nanocomposite microspheres could be detected was only several microns. Fig. 18 shows two tiny microspheres $(\sim 3-5 \mu \mathrm{m})$ under the 
TEM. They have a hybrid structure with two phases; namely the PLLA matrix and CHAp agglomerates more or less evenly distributed in the matrix. Recently, Wang et al. (2007) used TEM to characterize PHBV/HAp nanocomposite microspheres and they also obtained similar images as that shown in Fig. 18.

\subsection{Batch production for SLS}

The batch production was conducted on a five position magnetic stirrer and the beakers used had a capacity of 1 liter. The production conditions are listed in Table 1. Some PLLA microspheres produced are shown in Fig. 19 (a). They have a mean particle size of $30 \mu \mathrm{m}$ which is suitable for the SLS process.

\begin{tabular}{|l|l|}
\hline Production Condition & Value \\
\hline PLLA Concentration & $20 \mathrm{mg} / \mathrm{mL}$ \\
\hline PVA Concentration & $1 \mathrm{wt} \%$ \\
\hline Mixing Speed & $800 \mathrm{rpm}$ \\
\hline
\end{tabular}

Table 1. Conditions for batch production of PLLA microspheres for SLS.



(a)

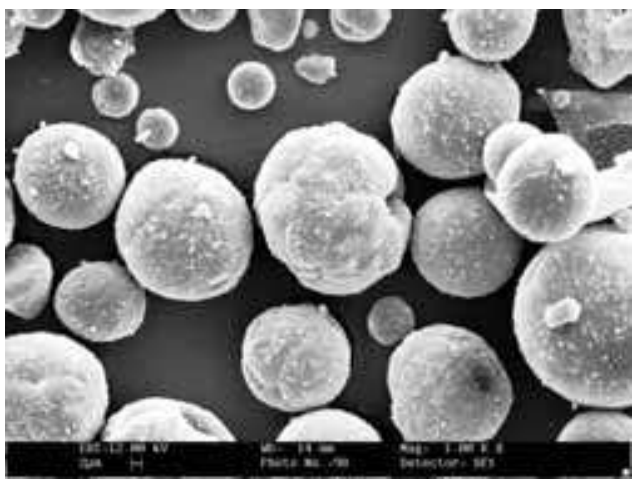

(b)

Fig. 19. SEM images of PLLA microspheres (a) and PLLA/CHAp nanocomposite microspheres $(b)$ prepared in batch production.

\begin{tabular}{|l|l|}
\hline Fabrication Condition & Value \\
\hline PLLA Concentration & $20 \mathrm{mg} / \mathrm{mL}$ \\
\hline CHAp:PLLA ratio & $1: 9$ \\
\hline PVA Concentration & $1 \mathrm{wt} \%$ \\
\hline Mixing Speed & $800 \mathrm{rpm}$ \\
\hline
\end{tabular}

Table 2. Conditions for batch production of PLLA/CHAp nanocomposite microspheres for SLS.

Table 2 shows the production condition of the PLLA/CHAp nanocomposite microspheres for the SLS process. Basically, it follows the preparation condition of the neat PLLA 
microspheres, only with the addition of $10 \mathrm{wt} \%$ CHAp into the organic phase. Some batch produced PLLA/CHAp microspheres are shown in Fig. 19 (b). Most of them are between 6 and $30 \mu \mathrm{m}$ in diameter and which is suitable for the SLS process. In the batch production, a homogenizer was used to disperse the CHAp nanospheres in the PLLA/DCM solution before mixing with the PVA aqueous solution to form emulsion. Also, it can be seen that some CHAp nanospheres are partially embedded on the PLLA/CHAp nanocomposite microspheres and this may impart bioactivity (osteoconductivity) for the scaffolds built.

\subsection{Discussion}

Among the numerous biomaterials developed for bone repair so far, polymer/apatite nanocomposite offers great potential for the successful regeneration of defective bony tissues. The advantage of this nanocomposite system is due to the fact that it mimics the structure and composition of extracellular bone matrix at the lowest structural level (Duan, Wang et al. 2008). The nanocomposites have been processed in different forms for specific applications, such as compressed or extruded molded part, thin film, and porous foam. Among the different formulations, polymer microspheres composed of apatites are of special interest in the treatment of bone defects. Practically, microspheres with a wide range of material compositions have been developed as a delivery vector for drugs and cells which can be released in a controlled manner for specific targeting. Moreover, the microspheres can be effectively injected into defects with minimal surgical invasion (Lemperle, Morhenn et al. 2004). For these reasons, the polymer/apatite nanocomposite microspheres are considered to be particularly useful for the repairing of bone defects by being implanted directly into the defective sites to repopulate osteoprogenitor cells or after ex vivo hybridization with osteogenic factors such as growth factors and cells. In such cases, the nanocomposite microspheres should have high potential in terms of their cell population and osteogenic stimulation (Kim, Gu et al. 2007). Moreover, the sintered microspheres matrix can be used as bone TE scaffolds.

The fabrication method for PLLA/CHAp nanocomposite microspheres is $\mathrm{S} / \mathrm{O} / \mathrm{W}$ emulsion solvent evaporation which is similar to the $\mathrm{W} / \mathrm{O} / \mathrm{W}$ emulsion solvent evaporation process used for the delivery of hydrophilic drug contained microspheres. The size of the PLLA/CHAp nanocomposite microspheres can be adjusted by the polymer and surfactant concentration and the mixing speed same as the PLLA microspheres. Meanwhile, the PLLA/CHAp microspheres are a suitable candidate for controlled delivery of recombinant human bone morphogenetic proteins (BMP) in solid form. The protein drugs could be protected by a layer of surfactant in order to avoid the denaturation of proteins by organic solvent. Thus the proteins may be incorporated along with the apatites into polymer microspheres to form a nanocomposite structure.

CHAp nanospheres may act as a colloid stabilizer (co-emulsifier) in the fabrication of PLLA/CHAp nanocomposite microspheres. Pickering (1907) stabilized emulsions by fine solid particles of different materials. This principle was known in ancient times when mustard powder was used to prepare mayonnaise by dispersing oil in water. These kinds of emulsions are termed Pickering emulsions, honoring the eponymous researcher who first described these systems a century ago. A wide variety of solid materials was reported as colloidal stabilizers. Examples are iron oxides and other oxides, hydroxides and oxyhydroxides, basic salts of metals, silica, barium sulfate, carbons, colloidal silver or solid organic materials such as glycerol stearate (Lagaly, Reese et al. 1999). Stabilization by solid 
materials requires the colloidal particles to form a dense film around the dispersed droplets which impedes coalescence when two droplets approach (the first mechanism). Enrichment of the fine particles at the oil/water interface is related to the contact angle $\theta$ at the wateroil-solid line. In general, stabilization is optimal when $\theta$ is somewhat below or above $90^{\circ}$. When $\theta$ is too small $\left(<<90^{\circ}\right)$ or too large $\left(>>90^{\circ}\right)$, the particles leave the interface and move into the continuous medium. A general rule is that $\mathrm{O} / \mathrm{W}$ emulsions are formed at $\theta<90^{\circ}$ and $\mathrm{W} / \mathrm{O}$ emulsions at $\theta>90^{\circ}$. A second stabilization mechanism is when the particles aggregate and build up a three-dimensional network in the coherent phase, the oil droplets can be trapped in the array of particles. The mechanical stability of the network structure reduces the rate of coalescence. Also, the network reduces the mobility of the particles and, in this way, enhances emulsion stability. The mechanism of CHAp nanosphere as the co-emulsifier is more likely the first mechanism which the stabilization is obtained by envelopes of CHAp nanospheres around the PLLA droplets. The mechanism of main emulsifier, PVA, is more likely as the second mechanism which the stabilization is obtained by forming a 3D network of PVA polymer chains. In fact, a novel surfactant-free process was proposed recently by modifying oil-in-water emulsion method to produce PLA/HAp composite microspheres (Nagata, Miyajima et al. 2003; Nagata, Miyajima et al. 2006; Nagata, Teraoka et al. 2006). Several analyses suggested that the end group of PLA would play as the nucleation site for HAp precipitates at the oil/water interface. The precipitated HAp might play a role as stabilizer for composite microsphere fabrication.

\section{Production of 3D porous laser sintered poly(L-Lactide) and poly(L- Lactide)/carbonated hydroxyapatite nanocomposite scaffolds}

A custom-made miniature sintering platform was installed in a commercial Sinterstation ${ }^{\circledR}$ 2000 SLS machine as shown in Fig. 20. This platform allowed the use of small quantities of
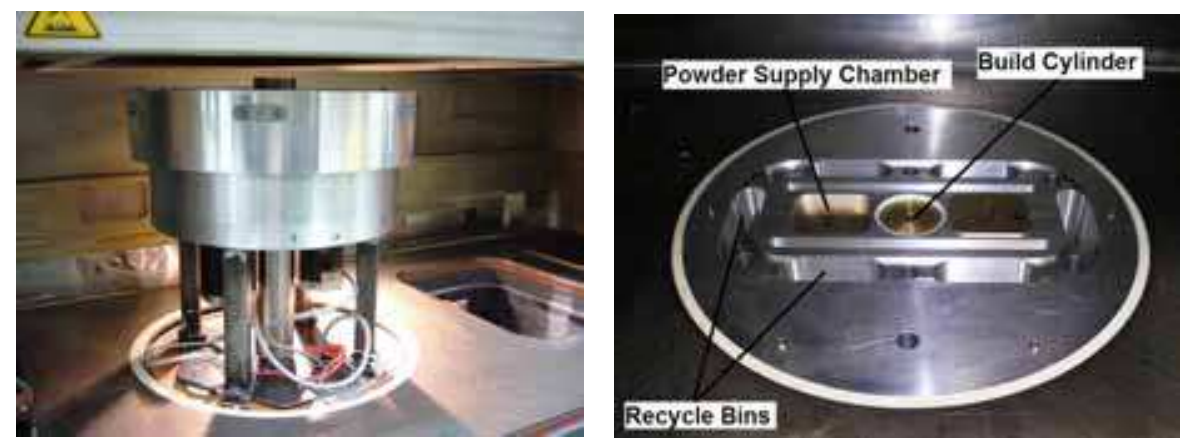

Fig. 20. Modification of Sinterstation ${ }^{\circledR} 2000$ system: miniature sintering platform before installation (left) and after installation (right).

biomaterials for TE scaffold production. The effects of laser power; scan spacing and part bed temperature were investigated and optimized, the details were discussed in another book chapter (Zhou, Wang et al. 2010). Finally, porous scaffolds were successfully fabricated from the PLLA microspheres and PLLA/CHAp nanocomposite microspheres as shown in Fig. 21 (a) and (b). In particular, the PLLA/CHAp nanocomposite microspheres appeared to be promising for porous bone TE scaffold production using the SLS technique. The structure 
and properties, e.g. porosity, compression properties, in vitro degradation behavior and cytocompatibility (such as cell adhesion and growth), of these scaffolds were evaluated (Zhou, Lee et al. 2008; Zhou, Wang et al. 2010). The nanocomposite scaffolds provide a biomimetic environment for osteoblastic cell attachment, proliferation and differentiation and have great potential for bone tissue engineering applications (Duan, Wang et al. 2010).

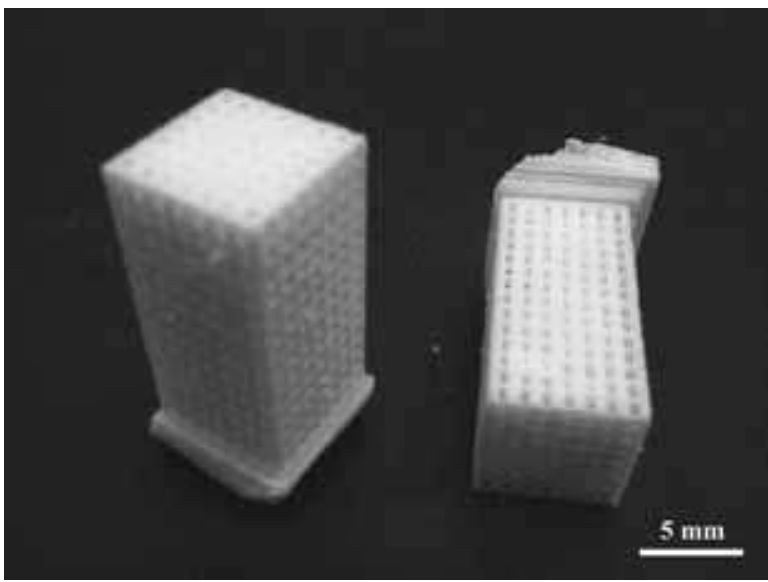

(a)

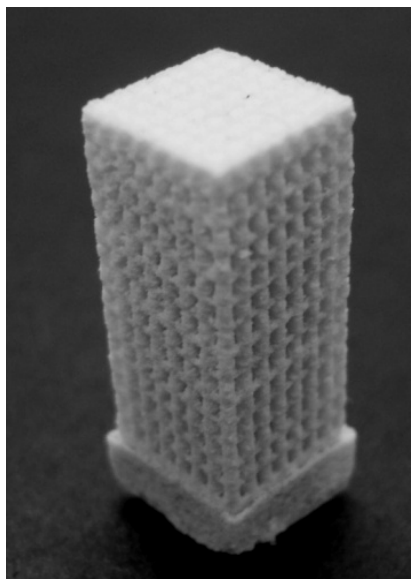

(b)

Fig. 21. (a) Selective laser sintered porous scaffolds from PLLA microspheres and (b) PLLA/CHAp nanocomposite microspheres .

\section{Conclusions}

The main part of this research focused on the synthesis and characterization of CHAp nanospheres through nanoemulsion; and on the fabrication and evaluation of the morphology of the PLLA microspheres and PLLA/CHAp nanocomposite microspheres as the bottom-up materials to build tissue engineering scaffolds. The custom-made miniature sintering platform allowed small quantities of the biomaterial powders to be processed in a commercial Sinterstation ${ }^{\circledR} 2000$ SLS machine. With this platform, prototypes of bone tissue engineering scaffolds with meso-scale feature were successfully built from PLLA microspheres and PLLA/CHAp nanocomposite microspheres.

\section{Acknowledgements}

This work was supported by a GRF research grant (HKU 7118/05E) from the Hong Kong Research Grants Council. Support by Prof. Bakr Rabie in the Faculty of Dentistry, HKU, is acknowledged.

\section{References}

Agrawal, C. M. and K. A. Athanasiou (1997). Technique to control pH in vicinity of biodegrading PLA-PGA implants. Journal of Biomedical Materials Research 38(2): 105114. 
Astala, R. and M. J. Stott (2005). First principles investigation of mineral component of bone: $\mathrm{CO}_{3}$ substitutions in hydroxyapatite. Chemistry of Materials 17(16): 4125-4133.

Barinov, S. M., J. V. Rau, et al. (2006). Carbonate release from carbonated hydroxyapatite in the wide temperature rage. Journal of Materials Science: Materials in Medicine 17(7): 597-604.

Barralet, J., S. Best, et al. (1998). Carbonate substitution in precipitated hydroxyapatite: An investigation into the effects of reaction temperature and bicarbonate ion concentration. Journal of Biomedical Materials Research 41(1): 79-86.

Barralet, J., J. C. Knowles, et al. (2002). Thermal decomposition of synthesised carbonate hydroxyapatite. Journal of Materials Science: Materials in Medicine 13(6): 529-533.

Barralet, J. E., S. M. Best, et al. (2000). Effect of sintering parameters on the density and microstructure of carbonate hydroxyapatite. Journal of Materials Science: Materials in Medicine 11(11): 719-724.

Benoit, J. P., F. Courteille, et al. (1986). A physicochemical study of the morphology of progesterone-loaded poly (L-lactide) microspheres. International Journal of Pharmaceutics 29(2-3): 95-102.

Bitz, C. and E. Doelker (1996). Influence of the preparation method on residual solvents in biodegradable microspheres. International Journal of Pharmaceutics 131(2): 171-181.

Bose, S. and S. K. Saha (2003). Synthesis and characterization of hydroxyapatite nanopowders by emulsion technique. Chemistry of Materials 15(23): 4464-4469.

Bouchemal, K., S. Briancon, et al. (2004). Nano-emulsion formulation using spontaneous emulsification: solvent, oil and surfactant optimisation. International Journal of Pharmaceutics 280(1-2): 241-251.

Boury, F., T. Ivanova, et al. (1995). Dilatational properties of adsorbed poly (D, L-lactide) and bovine serum albumin monolayers at the dichloromethane/water interface. Langmuir 11(5): 1636-1644.

Brunauer, S., P. H. Emmett, et al. (1938). Adsorption of gases in multimolecular layers. Journal of the American Chemical Society 60(2): 309-319.

Chorny, M., I. Fishbein, et al. (2002). Lipophilic drug loaded nanospheres prepared by nanoprecipitation: effect of formulation variables on size, drug recovery and release kinetics. Journal of Controlled Release 83(3): 389-400.

Curri, M. L., G. Leo, et al. (2001). CdS nanocrystals from a quaternary water-in-oil microemulsion: Preparation and characterization of self-assembled layers. Journal of Colloid and Interface Science 243(1): 165-170.

Doi, Y., H. Iwanaga, et al. (1999). Osteoclastic responses to various calcium phosphates in cell cultures. Journal of Biomedical Materials Research 47(3): 424-433.

Doi, Y., T. Koda, et al. (1993). Influence of carbonate on sintering of apatites. Journal of Dental Research 72(9): 1279-1284.

Duan, B., M. Wang, et al. (2008). Synthesis of Ca-P nanoparticles and fabrication of Ca$\mathrm{P} / \mathrm{PHBV}$ nanocomposite microspheres for bone tissue engineering applications. Applied Surface Science 255(2): 529-533.

Duan, B., M. Wang, et al. (2010). Three-dimensional nanocomposite scaffolds fabricated via selective laser sintering for bone tissue engineering. Acta Biomaterialia: 6(12): 44954505.

Fessi, H., F. Puisieux, et al. (1989). Nanocapsule formation by interfacial polymer deposition following solvent displacement. International Journal of Pharmaceutics 55(1): R1-R4. 
Forgiarini, A., J. Esquena, et al. (2001). Formation of nano-emulsions by low-energy emulsification methods at constant temperature. Langmuir 17(7): 2076-2083.

Freitas, M. N. and J. M. Marchetti (2005). Nimesulide PLA microspheres as a potential sustained release system for the treatment of inflammatory diseases. International Journal of Pharmaceutics 295(1-2): 201-211.

Freitas, S., H. P. Merkle, et al. (2005). Microencapsulation by solvent extraction/evaporation: reviewing the state of the art of microsphere preparation process technology. Journal of Controlled Release 102(2): 313-332.

Ganachaud, F. and J. L. Katz (2005). Nanoparticles and nanocapsules created using the Ouzo effect: Spontaneous emulsification as an alternative to ultrasonic and high-shear devices. Chemphyschem 6(2): 209-216.

Guo, X. and P. Xiao (2006). Effects of solvents on properties of nanocrystalline hydroxyapatite produced from hydrothermal process. Journal of the European Ceramic Society 26(15): 3383-3391.

Hasegawa, M., Y. Doi, et al. (2003). Cell-mediated bioresorption of sintered carbonate apatite in rabbits. Journal of Bone and Joint Surgery, British Volume 85B(1): 142-147.

Ishikawa, K. and E. D. Eanes (1993). The hydrolysis of anhydrous dicalcium phosphate into hydroxyapatite. Journal of Dental Research 72(2): 474-480.

Izquierdo, P., J. Esquena, et al. (2002). Formation and stability of nano-emulsions prepared using the phase inversion temperature method. Langmuir 18(1): 26-30.

Izquierdo, P., J. Esquena, et al. (2004). Phase behavior and nano-emulsion formation by the phase inversion temperature method. Langmuir 20(16): 6594-6598.

Jeffery, H., S. S. Davis, et al. (1991). The preparation and characterisation of poly (lactide-coglycolide) microparticles. I: Oil-in-water emulsion solvent evaporation. International Journal of Pharmaceutics 77(2-3): 169-175.

Kalapos, M. P. (2003). On the mammalian acetone metabolism: from chemistry to clinical implications. Biochimica et Biophysica Acta 1621(2): 122-139.

Kawai, T., Y. Usui, et al. (1999). Synthesis and growth mechanism of GeO2 particles in AOT reversed micelles. Colloids and Surfaces A: Physicochemical and Engineering Aspects 149(1-3): 39-47.

Kim, H. W., H. J. Gu, et al. (2007). Microspheres of collagen-apatite nanocomposites with osteogenic potential for tissue engineering. Tissue Engineering 13(5): 965-973.

Kuksis, A., A. Ravandi, et al. (2005). Covalent binding of acetone to aminophospholipids in vitro and in vivo. Annals of the New York Academy of Sciences 1043(1): 417-439.

Lagaly, G., M. Reese, et al. (1999). Smectites as colloidal stabilizers of emulsions: I. Preparation and properties of emulsions with smectites and nonionic surfactants. Applied Clay Science 14(1-3): 83-103.

Landi, E., G. Celotti, et al. (2003). Carbonated hydroxyapatite as bone substitute. Journal of the European Ceramic Society 23(15): 2931-2937.

Landi, E., A. Tampieri, et al. (2005). Nucleation of biomimetic apatite in synthetic body fluids: dense and porous scaffold development. Biomaterials 26(16): 2835-2845.

Landi, E., A. Tampieri, et al. (2000). Densification behaviour and mechanisms of synthetic hydroxyapatites. Journal of the European Ceramic Society 20(14-15): 2377-2387.

Lee, S. C., J. T. Oh, et al. (1999). Quantitative analysis of polyvinyl alcohol on the surface of poly(d,l-lactide-co-glycolide) microparticles prepared by solvent evaporation method: effect of particle size and PVA concentration. Journal of Controlled Release 59(2): 123-132. 
Lee, S. H. (2006). M.Phil. Thesis: Feasibility Study of Selective Laser Sintering of Biopolymer Scaffolds for Tissue Engineering, the University of Hong Kong.

LeGeros, R. Z. and J. P. LeGeros (1993). Dense Hydroxyapatite. An Introduction to Bioceramics. L. L. Hench and J. Wilson, World Scientific 139-180.

LeGeros, R. Z., O. R. Trautz, et al. (1969). Two types of carbonate substitution in the apatite structure. Experientia 25(1): 5-7.

Lemperle, G., V. B. Morhenn, et al. (2004). Migration studies and histology of injectable microspheres of different sizes in mice. Plastic and Reconstructive Surgery 113(5): 1380-1390.

Liu, D.-M., T. Troczynski, et al. (2001). Water-based sol-gel synthesis of hydroxyapatite: process development. Biomaterials 22(13): 1721-1730.

Mu, L. and S. S. Feng (2001). Fabrication, characterization and in vitro release of paclitaxel (Taxol) loaded poly (lactic-co-glycolic acid) microspheres prepared by spray drying technique with lipid/cholesterol emulsifiers. Journal of Controlled Release 76(3): 239254.

Nagata, F., T. Miyajima, et al. (2003). Surfactant-free preparation of poly(lactic acid)/hydroxyapatite microspheres. Chemistry Letters 32(9): 784-785.

Nagata, F., T. Miyajima, et al. (2006). A method to fabricate hydroxyapatite/poly (lactic acid) microspheres intended for biomedical application. Journal of the European Ceramic Society 26(4-5): 533-535.

Nagata, F., K. Teraoka, et al. (2006). Double layered microshells composed of calcium phosphate and poly (lactic acid). Bioceramics 18, Pts 1 and 2. 309-311: 915-918.

Nelson, D. G. A. and J. D. B. Featherstone (1982). Preparation, Analysis, and Characterization of Carbonated Apatites. Calcified Tissue International 34: S69-S81.

Okada, M. and T. Furuzono (2007). Nano-sized ceramic particles of hydroxyapatite calcined with an anti-sintering agent. Journal of Nanoscience and Nanotechnology 7(3): 848-851.

Partee, B., S. J. Hollister, et al. (2006). Selective laser sintering process optimization for layered manufacturing of CAPA (R) 6501 polycaprolactone bone tissue engineering scaffolds. Journal of Manufacturing Science and Engineering 128(2): 531-540.

Pickering, S. U. (1907). Emulsions. J. Chem. Soc. Trans. 97: 2001-2021.

Puajindanetr, S., S. M. Best, et al. (1994). Characterization and sintering of precipitated hydroxyapatite. British Ceramic Transactions 93(3): 96-99.

Rao, R. R., H. N. Roopa, et al. (1997). Solid state synthesis and thermal stability of HAP and HAP - beta-TCP composite ceramic powders. Journal of Materials Science: Materials in Medicine 8(8): 511-518.

Re, M.-I. (2006). Formulating drug delivery systems by spray drying. Drying Technology 24(4): 433-446.

Reisman, D. J. (1998). Acetone : first draft. Geneva, World Health Organization.

Rey, C., V. Renugopalakrishnan, et al. (1991). Fourier-transform infrared spectroscopic study of the carbonate ions in bone-mineral during aging. Calcified Tissue International 49(4): 251-258.

Sahoo, S. K., J. Panyam, et al. (2002). Residual polyvinyl alcohol associated with poly (,lactide-co-glycolide) nanoparticles affects their physical properties and cellular uptake. Journal of Controlled Release 82(1): 105-114.

Shakesheff, K. M., C. Evora, et al. (1997). The adsorption of poly(vinyl alcohol) to biodegradable microparticles studied by X-ray photoelectron spectroscopy (XPS). Journal of Colloid and Interface Science 185(2): 538-547. 
Siepmann, J. and F. Siepmann (2006). Microparticles Used as Drug Delivery Systems. Smart Colloidal Materials: 15-21.

Solans, C., P. Izquierdo, et al. (2005). Nano-emulsions. Current Opinion in Colloid \& Interface Science 10(3-4): 102-110.

Tadic, D., F. Peters, et al. (2002). Continuous synthesis of amorphous carbonated apatites. Biomaterials 23(12): 2553-2559.

Tewes, F., F. Boury, et al. (2006). Biodegradable microspheres: advances in production technology. Microencapsulation: methods and industrial applications. S. Benita. New York Taylor \& Francis: 2-5.

Thomasin, C., P. Johansen, et al. (1996). A contribution to overcoming the problem of residual solvents in biodegradable microspheres prepared by coacervation. European Journal of Pharmaceutics and Biopharmaceutics 42(1): 16-24.

Uota, M., H. Arakawa, et al. (2005). Synthesis of high surface area hydroxyapatite nanoparticles by mixed surfactant-mediated approach. Langmuir 21(10): 4724-4728.

Uson, N., M. J. Garcia, et al. (2004). Formation of water-in-oil (W/O) nano-emulsions in a water/mixed non-ionic surfactant/oil systems prepared by a low-energy emulsification method. Colloids and Surfaces A: Physicochemical and Engineering Aspects 250(1-3): 415-421.

USP25-NF20 (2002). Organic volatile impurities. The United States Pharmacopeia (USP 25); The National Formulary (NF 20) Rockville, MD., United States Pharmacopeial Convention, Inc.

Wang, M. (2003). Developing bioactive composite materials for tissue replacement. Biomaterials 24(13): 2133-2151.

Wang, Y., X. Wang, et al. (2007). Fabrication, characterization and long-term in vitro release of hydrophilic drug using PHBV/HA composite microspheres. Materials Letters 61(4-5): 1071-1076.

Yang, F., W. Cui, et al. (2006). Poly(l,l-lactide-co-glycolide)/tricalcium phosphate composite scaffold and its various changes during degradation in vitro. Polymer Degradation and Stability 91(12): 3065-3073.

Zambaux, M. F., F. Bonneaux, et al. (1998). Influence of experimental parameters on the characteristics of poly(lactic acid) nanoparticles prepared by a double emulsion method. Journal of Controlled Release 50(1-3): 31-40.

Zhou, W. Y., S. H. Lee, et al. (2007). Selective laser sintering of tissue engineering scaffolds using poly(L-Lactide) microspheres. Key Engineering Materials 334-335: 1225-1228.

Zhou, W. Y., S. H. Lee, et al. (2008). Selective laser sintering of porous tissue engineering scaffolds from poly(L-lactide)/carbonated hydroxyapatite nanocomposite microspheres. Journal of Materials Science: Materials in Medicine 19(7): 2535-2540.

Zhou, W. Y., M. Wang, et al. (2008). Synthesis of carbonted hydroxyapatite nanospheres through nanoemulsion. Journal of Materials Science: Materials in Medicine 19(1): 103110.

Zhou, W. Y., M. Wang, et al. (2007). Fabrication and characterization of composite microspheres containing carbonated hydroxyapatite nanoparticles. Key Engineering Materials 334-335: 1221-1224.

Zhou, W. Y., M. Wang, et al. (2010). Selective Laser Sintering of Poly(L-Lactide)/Carbonated Hydroxyapatite Nanocomposite Porous Scaffolds for Bone Tissue Engineering. Tissue Engineering. D. Eberli. Vienna, Austria, IN-TECH: 179-204. 


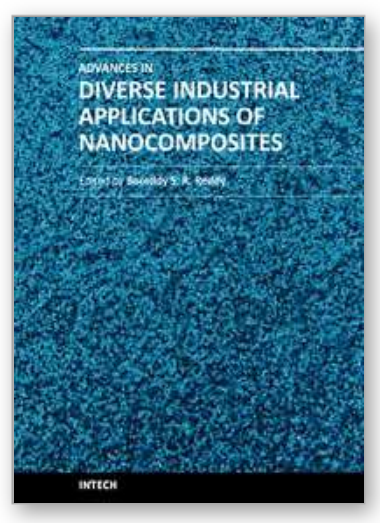

\author{
Advances in Diverse Industrial Applications of Nanocomposites \\ Edited by Dr. Boreddy Reddy
}

ISBN 978-953-307-202-9

Hard cover, 550 pages

Publisher InTech

Published online 22, March, 2011

Published in print edition March, 2011

Nanocomposites are attractive to researchers both from practical and theoretical point of view because of combination of special properties. Many efforts have been made in the last two decades using novel nanotechnology and nanoscience knowledge in order to get nanomaterials with determined functionality. This book focuses on polymer nanocomposites and their possible divergent applications. There has been enormous interest in the commercialization of nanocomposites for a variety of applications, and a number of these applications can already be found in industry. This book comprehensively deals with the divergent applications of nanocomposites comprising of 22 chapters.

\title{
How to reference
}

In order to correctly reference this scholarly work, feel free to copy and paste the following:

Wen You Zhou, Min Wang and Wai Lam Cheung (2011). Selective Laser Sintered Poly(L-Lactide)/Carbonated Hydroxyapatite Nanocomposite Scaffolds: A Bottom-up Approach, Advances in Diverse Industrial Applications of Nanocomposites, Dr. Boreddy Reddy (Ed.), ISBN: 978-953-307-202-9, InTech, Available from: http://www.intechopen.com/books/advances-in-diverse-industrial-applications-of-nanocomposites/selectivelaser-sintered-poly-l-lactide-carbonated-hydroxyapatite-nanocomposite-scaffolds-a-bottom-u

\section{INTECH}

open science | open minds

\section{InTech Europe}

University Campus STeP Ri

Slavka Krautzeka 83/A

51000 Rijeka, Croatia

Phone: +385 (51) 770447

Fax: +385 (51) 686166

www.intechopen.com

\section{InTech China}

Unit 405, Office Block, Hotel Equatorial Shanghai

No.65, Yan An Road (West), Shanghai, 200040, China

中国上海市延安西路65号上海国际贵都大饭店办公楼 405 单元

Phone: +86-21-62489820

Fax: $+86-21-62489821$ 
(C) 2011 The Author(s). Licensee IntechOpen. This chapter is distributed under the terms of the Creative Commons Attribution-NonCommercialShareAlike-3.0 License, which permits use, distribution and reproduction for non-commercial purposes, provided the original is properly cited and derivative works building on this content are distributed under the same license. 